\title{
Developments in encapsulation of insulin: Is oral delivery now possible?
}

\author{
Anubhav Pratap Singh ${ }^{1^{*}} \quad$ Yigong Guo $^{1} \quad$ Anika Singh $^{1} \quad$ Wen Xie $^{1} \quad$ Patrick Jiang $^{1}$
}

\begin{abstract}
This review presents the possibilities of oral delivery of insulin. Insulin, being readily destroyed/transformed by the proteolytic enzymes and first-pass effects in the digestive system, has mainly been administered through injection, such as intravenous injection and transdermal injection. With developments in the material sciences, appropriate encapsulation methodologies have been developed that could be employed to protect insulin from the digestive effects of the human GI system, and thereby have opened a gateway of research exploring the oral route of insulin delivery. One approach is to incorporate insulin into an emulsion with an appropriate oil-phase, which protects the insulin from degradation. Coating with natural or synthetic polymeric materials, or with lipids, followed by size-reduction to $100-1000 \mathrm{~nm}$ is applied as another common approaches of insulin encapsulation. Other approaches like liposomes, nanogels, etc. are also being explored. This review gives a summary of methods of preparation as well as in vitro and in vivo bioavailability of insulin through these methods. It is observed that the oral bioavailability of insulin intake has increased from about $0.1 \%$ to about $20 \%$ for encapsulated insulin.
\end{abstract}

Keywords: insulin, oral delivery, encapsulation, materials

\section{Introduction}

Diabetes is a worldwide disease that causes millions of deaths annually ${ }^{[1]}$. The inherent cause of diabetes is the inability of the body to produce or utilize insulin, a polypeptile hormone produced naturally by the pancreatic beta cells of a healthy individual on rise in blood glucose level (after digestion of food) ${ }^{[2]}$. This compound controls blood glucose levels by protecting the islet beta cells, promoting the uptake and utilization of glucose in tissues and cells and accelerating glycogen, fatty acid and protein synthesis ${ }^{[3]}$. Non-availability of enough insulin during diabetes causes hyperglycemia which leads to various derived disorders, such as diabetic ketoacidosis, hyperosmolar hyperglycemic state, cardiovascular disease, stroke, chronic kidney disease, foot ulcers, $e t c^{[4]}$. In contrast, if blood glucose level is low, the amount of insulin in the blood will decrease and then glycogen will breakdown to glucose ${ }^{[2]}$. Normally, diabetes can be classified into three types: type 1 diabetes

Received: June 22, 2019 Accepted: August 3, 2019 Published: August 5, 2019

* Correspondence to: Anubhav Pratap Singh, Food Nutrition and Health Program, Faculty of Land and Food Systems, University of British Columbia, Vancouver, Canada; Email: anubhav.singh@ubc.ca

${ }^{1}$ Food Nutrition and Health Program, Faculty of Land and Food Systems, University of British Columbia, Vancouver, Canada

Citation: Pratap Singh A, Guo YG, Singh A, et al. Developments in encapsulation of insulin: Is oral delivery now possible? J Pharm Biopharm Res, 2019, 1(2): 74-92.

Copyright: (c) 2019 Anubhav Pratap Singh, et al. This is an open access article distributed under the terms of the Creative Commons Attribution License, which permits unrestricted use, distribution, and reproduction in any medium, provided the original author and source are credited. means patients produce no or very little insulin in their bodies $^{[5]}$; type 2 diabetes means patients cannot use insulin efficiently though insulin is produced at normal levels ${ }^{[6]}$; and a third type of diabetes, also known as gestational diabetes mellitus, which often occurs during pregnancy and disappear after childbirth ${ }^{[3]}$.

Data published by WHO showed that almost 3 million people over the world die from diabetes each year, with $95 \%$ of the cases attributed to type 2 diabetes $^{[7]}$. What's more alarming is the fact that if diabetes is not controlled appropriately, the number of death would be 380 million in the year of $2025^{[8]}$. To prevent that from happening, people should pay more attention to the diagnosis and prevention of diabetes.

Insulin (INS) was first isolated and identified from the pancreas in 1922 by Banting and Best, which significantly improves the living standard of patients with diabetes, especially those with type 1 . With a molecular weight of about 6000, it is considered a high-molecularweight protein that can easily be decomposed by the proteolytic enzyme and eliminated by the first-pass effect of the liver. Additionally, due to its high molecular weight, it can easily be aggregated, which makes it hard to be absorbed. In order to overcome such negative effect, people are administered with insulin through injection especially for the intravenous route ${ }^{[9,10]}$. Patients with type I diabetes need to be injected with insulin throughout their whole life period once they are diagnosed. This has brought great pain and inconve- 


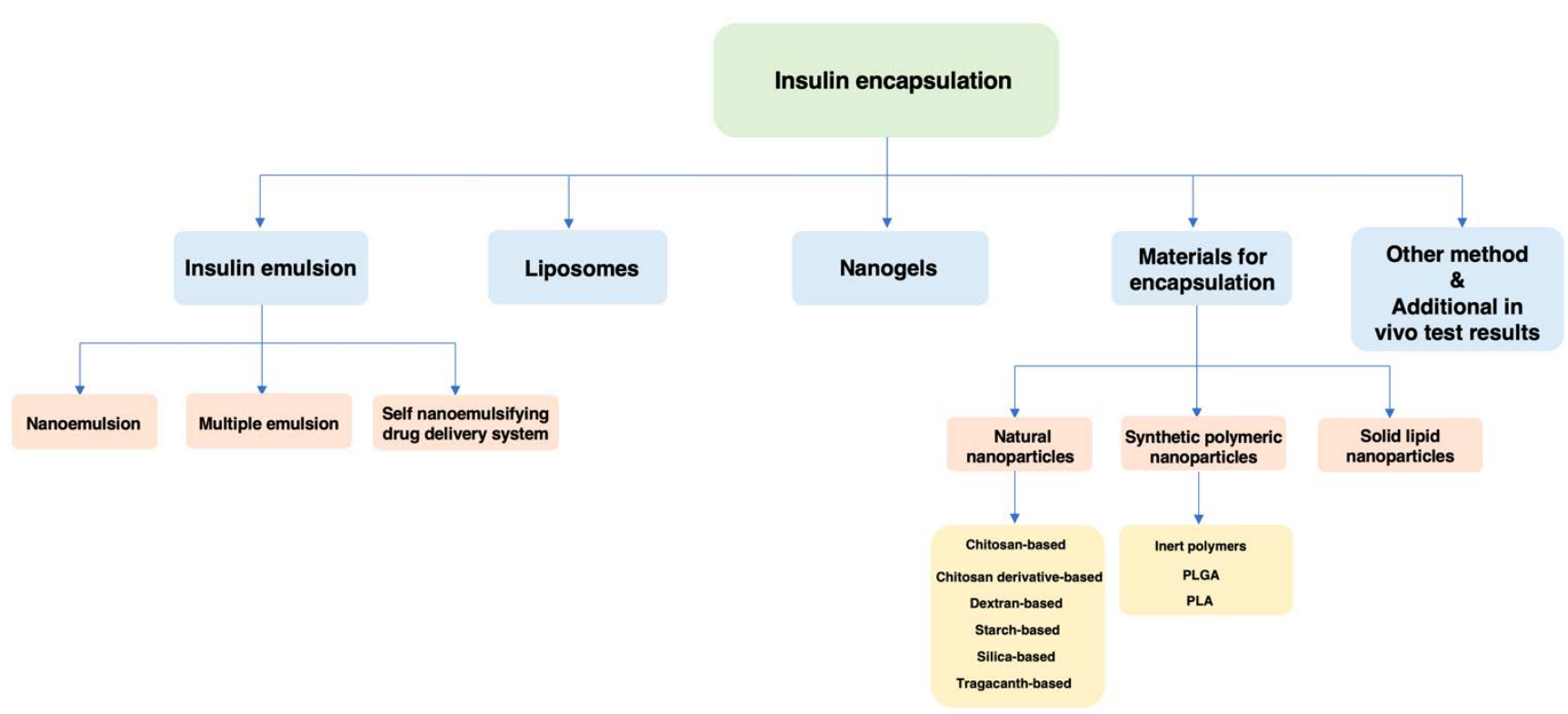

Figure 1. Scope of types and fabrication methods of insulin encapsulation covered in this review

nience to patients, accompanied by various adverse reactions. To reduce the negative effect and enhance the living standard of the patients, new methods of administration are being explored. Despite the appearance of the insulin pump, also known as continuous subcutaneous insulin infusion (CSII), it still brings various health risks to patients due to pump failure, insulin infusion set (IIS) blockage, in-fusion site problems, insulin stability issues, user error, etc. ${ }^{[11]}$ Therefore, researchers have started to pay more attention to oral intake of insulin. However, the bioavailability of taking insulin orally is less than $0.1 \%^{[12]}$, which increases only slightly with use of enzyme inhibitors like those identified from DNAtemplated macro-cycle libraries ${ }^{[13]}$, some absorption enhancers like Gelucire 44/14 etc. ${ }^{[14]}$ A more promising way to enhance the bioavailability of insulin is to encapsulate it with appropriate materials.

Nanoemulsions (NEs), liposomes (LIs) and nanogels are three efficient encapsulation techniques. They can encapsulate and protect the insulin from degradation in the stomach and release them in specific parts of the digestive tract. In this review, developments and approaches of encapsulation of insulin is discussed and emphasized. This review mainly focuses on recent studies on methods and materials used for encapsulating insulin and some in-vivo results of current studies (shown in Figure 1).

\section{Insulin emulsion}

An emulsion is a fine dispersion of minute droplets of two insoluble and immiscible liquids. Insulin emul- sion involves dissolving insulin with other liquids and homogenizing the mixture to increase phase dispersion, followed by solvent evaporation the method is often referred to as 'solvent evaporation method'. As defined by International Union of Pure and Applied Chemistry (IUPAC), emulsions are "clear, thermodynamically stable, isotropic liquid mixtures of oil, water and surfactant, often in combination with a cosurfactant'. The aqueous phase contains salt or other ingredients, and the 'oil' could be a complex mixture of different hydrocarbons and olefins. In the case of nano-emulsion, an aqueous solution of insulin is dissolved in an organic solution of polymers. In the case of multiple emulsion, insulin is first dissolved in the aqueous phase, then mixed into oil phase to form water-in-oil primary emulsion, which is then re-emulsified into an oil phase for the formation of the double emulsion. Multiple emulsions provide better encapsulation efficiency with prolonged drug release due to better protection of dissolved drug by 2 layers. In addition, self nano-emulsifying drug delivery systems is another potential method to encapsulate insulin. Depending on the mode of delivery, these emulsions could be lyophilized or spray-dried into nanoparticles, or given directly, or converted into gels. Thus, often a combination of emulsion method with other methods is also demonstrated. The three most common emulsion method of preparation are introduced in this section.

\subsection{Nano-emulsions}

In contrast to ordinary emulsions, nano-emulsion is a colloidal dispersion system of 10-100 $\mathrm{nm}$ emulsion 
droplets dispersed in another liquid. They form upon simple mixing of the components and do not require the high shear conditions generally used for the formation of ordinary emulsions. As an oral insulin carrier, aside from good permeability because of their small size, nano-emulsion can also invert phase upon changing the amount of disperse phase and ambient temperature (e.g. body temperature), thereby releasing drugs to the bloodstream and inhibit diabetes. The key to forming nanoemulsion is to select an appropriate aqueous phase, oil phase, emulsifier, and co-emulsifier so that the activity of drugs can be maintained in the process of preparation.

Different materials are used to prepare nanoemulsions, such as lecithin by Cilek et al. and Eudragit S100 by Jain et al. ${ }^{[15,16]}$ Cilek et al. found that the size of nano-emulsion largely dependent on the purity of lecithin and the mixing ratio between surfactant (lecithin) and co-surfactant (alcohol) ${ }^{[15]}$. Besides, the nature of nano-emulsion does not change with the storage temperature ${ }^{[15,16]}$. Jain et al. ${ }^{[16]}$ prepared nanoemulsion using Eudragit S100 (an acrylic resin pH regulating and releasing agent), and added Polysorbate-20 and Polyvinyl alcohol (PVA) to internal and external water phases as dispersants and stabilizers respectively. After it was given to rabbits orally, their blood glucose dropped to $(76 \pm 3) \%$ within 2 hours and the effect lasted 6 hours ${ }^{[16]}$. Thus, this kind of nano-emulsion could be an oral carrier for insulin and could be a potential mean to encapsulate the same. However, duration of activity of nano-emulsions is shorter compared with nanoparticles. Consequently, other effective emulsion techniques are being explored.

Barbari et al. ${ }^{[17]}$ developed a novel nano-emulsion based method to produce ultra-small, water-dispersed nanoparticles from chitosan. The nano-sized $(50 \mathrm{~nm})$ water pools of the water-in-oil nano-emulsion served as 'nano-containers and nano-reactors', which could enhance the efficiency of the chitosan nanoparticles (discussed in Section 3). Under this situation, the chitosan nanoparticles could tolerate an extended $\mathrm{pH}$ range and showed more ability to penetrate through the Caco-2 cell (15\%-19\% bioavailability). However, they did not show the in-vivo results, which is important to establish this method as the standalone method of insulin administration.

\subsection{Multiple emulsion}

In order to enhance the efficiency of the emulsion, a bilayer or multilayer emulsion offers the potential to control the diffusion rate of drugs more effectively, sustainably and with better control. On the other hand, multiple emulsion can keep protein and polypeptide drugs in the internal water phase well and avoid the damage of digestive enzymes in the gastrointestinal tract. The release mechanism of $\mathrm{W} / \mathrm{O} / \mathrm{W}$ insulin from the emulsion is that emulsion particles are diluted, followed by expanding and bursting in a hypotonic environment, during which insulin can be released ${ }^{[18]}$.

Mutaliyeva et al..$^{[19]}$ developed an approach to encapsulate insulin by a modified double emulsion method (preparative procedure shown in Figure 2). The results showed that this method could optimize the physicochemical properties of insulin-loaded Ch-Xan Gum nanoparticles with a process yield of $65.677 .5 \%$, and association efficiency of $85.3 \%$. Additionally, it could control the release of insulin in 3 hours. Cournarie et al. ${ }^{[20]}$ compared the properties of emulsion systems prepared with medium-chain triglyceride and long-chain triglyceride respectively. Long-chain triglyceride had higher viscosity and surface tension. After being taken by mice orally, the insulin emulsion showed a good curative effect. Insulin multiple-emulsions prepared with mediumchain triglyceride had a smaller particle size and was more stable compared to long-chain triglyceride preparations. In order to prepare multiple emulsion with a better effect, these two substances could be combined. Toorisaka et al. ${ }^{[21]}$ reported that $\mathrm{W} / \mathrm{O} / \mathrm{W}$ insulin multiple emulsion shows long-term hypoglycemic activity. They also found that adding vegetable oil to multiple emulsion as a surfactant and using $\mathrm{pH}$-sensitive polymer as an enteric coating material produces a better insulin release behavior. Thus, multiple emulsion methods is now regarded as an established method in literature, and above recent researches demonstrate an emerging potential of this technique being used for oral insulin delivery.

\subsection{Self-nanoemulsifying drug delivery sys- tem (SNEDDS)}

Self nano-emulsifying drug delivery systems (SNEDDS) are emulsion systems that are designed to be spontaneously favorable towards emulsion formation. This happens because of extremely low interfacial tension between the oil and aqueous phases, with the presence of surfactants and co-surfactants. The application of SNEDDS is generating increasing attention because of its excellent bioavailability. A wide range of aqueous phase, oil phase, surfactants and co-surfactants are used by different groups of researchers ${ }^{[22]}$, and the ratio of oil to Smix (surfactant, solvent and co-solvent) is optimized. Miglyol 840, Captex 355 and Capmul MCM, Lauroglycol FCC, Labrafil M1944CS, Oleic acid, Peceol and Caproyl-90 can potentially be used as oil phases, Tween 80, cremophor EL and DSAB, Transcutol HP can function as surfactants and PEG-400 


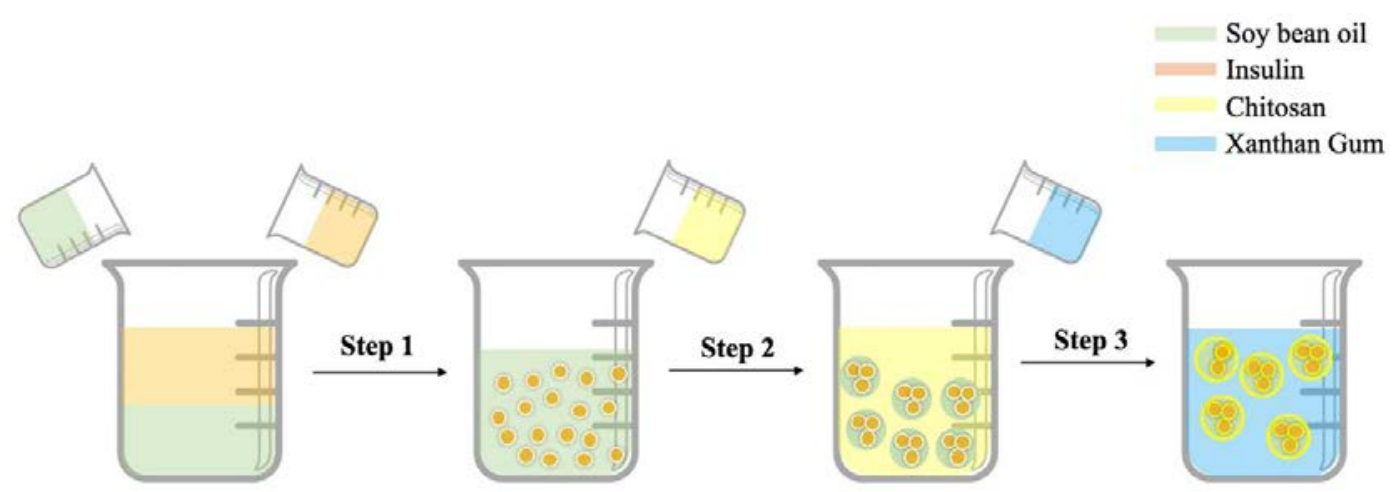

Figure 2. The preparative procedure of insulin encapsulation: (step 1) Emulsification; (step 2) Re-emulsification producing a double emulsion; (step 3) Addition of Xanthan Gum to stabilize the droplets of double emulsion with biopolymers shells ${ }^{[19]}$

and Propylene glycol function as co-surfactants. The small droplet-size of less than $200 \mathrm{~nm}$ allows for easier cellular uptake. In these research papers, optimized formulations are explored by comparing the emulsification properties as emulsification time and size of droplets, by means of experimental design ${ }^{[22]}$.

Sakloetsakun et al. combined the use of SNEDDS with encapsulated chitosan nanoparticles, taking advantage of the mucoadhesive properties exhibited by chi$\operatorname{tosan}^{[22]}$. SNEDDS has proved to be associated with a small particles size of around $100 \mathrm{~nm}$ and high entrapment efficiency of higher than $70 \%$, even up to $90 \%$ or higher in some cases. Karamanidou et al. also used SNEDDS method to form of an INS/ dimyristoyl phosphatidyl-glycerol (DMPG) ionic complex with $70.89 \%$ encapsulation efficiencies. In vitro test showed that the developed SNEDDS formulation for oral insulin delivery protected the therapeutic protein from enzymatic degradation by intestinal enzymes (i.e., trypsin, a-chymotrypsin ${ }^{[23]}$. These findings showed that the developed SNEDDS formulation could be considered as a novel delivery system for the oral administration of insulin.

\section{Liposomes}

The negatively charged liposome is one of the components of most biofilms. It consists of phospholipid bilayers and stays in the form of colloidal dispersion in aqueous buffers ${ }^{[24]}$. Liposome mainly consists twopart, one being the inner part, with polar headgroups of phospholipids and the other one being the hydrophobic carbohydrate tails ${ }^{[25]}$. After some specific compounds, both hydrophobic and hydrophilic, are encapsulated by the liposomes, it can help these compounds deal with some enzymatic degradation effects. If liposome is combined with biological cells and wraps compounds synchronously, the entrapment efficiency of will be im- proved and the stability will be optimized ${ }^{[26,27]}$. Additionally, it can also help these compounds be released to some target organs. Liposome performs as a carrier and releases insulin through fusion and surface adsorption of intestinal cytomembrane ${ }^{[28]}$. The size of the liposome varies a lot by different purposes, ranging from 40-50 $\mathrm{nm}$ to $1-2 \mu \mathrm{m}^{[29]}$. One apparent goal of encapsulating some compounds like insulin into the liposome is that it can enhance the therapeutic of these compounds in many ways. The high affinity of biological lipid membrane can help big molecules permeate somatic cells. Liposome combined with insulin is known as HDVI (hepatocyte directed vesicle with insulin) and can be hepatocytetargeted. It was of great significance to recover liver function and circulatory function of patients with diabetes as soon as possible ${ }^{[26]}$. What's more, because of its biodegradable effect and high bioaffinity, it can be safely utilized as a material of food application in vivo ${ }^{[30]}$.

In order to make it easily used in food administration, it should be designed properly. The key strategy of designing the liposome is controlling the releasing time and location. Lipid composition, surface charge, and vesicular size can all affect this goal tremendously. Moreover, as the fluidity and the rigidity of the bilayer can also affect the release and the control of liposomal compounds like insulin, many studies have been conducted on the effects of phospholipids at different phase transition temperatures on fluidity, and the effects of lipid composition on the rigidity of liposomes ${ }^{[31]}$.

To make the liposome safer for oral delivery of insulin, Cui et al raised a special modified liposome to load insulin. The protective ability of this kind is generated by ergosterol (Er-Lip), which is a type of botanical steroidal, instead of cholesterol. The protective mechanism was similar to that of liposomes containing sodium glycocholate (Sgc-Lip) and superior to that of liposomes containing cholesterol (Ch-Lip) ${ }^{[32]}$. In addition, the blood glucose level can decrease to about $50 \%$ of the 
initial level after this kind of liposomes was taken orally, which was significantly superior to the in vivo effect of the Ch-Lip and similar to the Sgc-Lip ${ }^{[32]}$. The results of their study showed that liposomes being used to protect insulin for food administration could be both effective and safe.

Zhang et al. studied active ingredients in the liposome. Liposome containing DPPC (dipalmitoyl phosphatidylcholine)-cholesterol is used and added with MC (methylcellulose) as a mucosal adhesive. After the liposome being orally administered to rats, it is observed that the blood glucose is dropped. The role of phospholipid component (a composite of DPPC, cholesterol and MC) was very crucial. Besides, $\mathrm{pH}$ value, active sites of protamine sulfate and liposome also mattered a $\operatorname{lot}^{[33]}$.

Interestingly, one recent study produced a unique bile acid conjugated partially uncapped liposome to deliver insulin. They first made the chondroitin sulfategtaurocholic acid coated, insulin-loaded partially uncapped liposome (IPUL-CST). The insulin-loaded partially uncapped liposome (IPUL) was first made by dimethyl dioctadecyl ammonium bromide (DDAB), deoxycholic acid (DOCA), and $10 \mathrm{~nm}$ size of superparamagnetic iron oxide nanoparticles dissolved in chloroform. After insulin was loaded into this liposome, the insulinloaded liposome was then coated with a chondroitin sulfateTCA conjugate (CST). This unprecedented uncapped liposome can increase the oral bioavailability of insulin to $34 \%$ lasting 16 hours $^{[34]}$.

As a carrier, the problems of not being stable enough, easy to aggregate and coalesce, making liposome hard to absorb wrapped drugs. People tried different methods to overcome these defects, such as adding a second surfactant to the bimolecular film of the liposome, modification with charged chemicals or chemical groups, linking lipid molecules that constitute membrane structure by covalent bonds and production of the polymeric liposome, etc. To improve the stability of drug-loaded liposome, scientists linked the outer end of each lipid molecule that formed liposome with covalent bonds, forming polymeric liposome on the surface of the membrane. Recently, Degim et al. pointed out that liposome insulin modified by wheat germ agglutinin (WGA) had good absorptivity. The ileum is the best part to absorb liposome insulin. However, the protein degradation and epithelial permeation were main factors affecting the mucosal absorption of insulin ${ }^{[35]}$. Wang et al studied the oral absorption mechanism of insulin liposome at the cellular level and found that insulin wrapped by liposome can be absorbed both intracellularly and extracellularly. By comparing intracellular absorption of insulin and insulin liposome using ELISA, it turned out that the permeability of the latter was significantly higher than that of the former one, suggesting that liposome entrapment can promote the intracellular absorption of insulin ${ }^{[36]}$.

\section{Nanogel}

Gel particle is a kind of three-dimensional reticular spatial structure obtained by physical crosslinking. Due to its high hydrophilia, good biocompatibility, it is becoming one of the most promising oral delivery biomaterials. It has recently widely been used in drug delivery and tissue engineering ${ }^{[37]}$. Gel particle is crosslinked by weak non-covalent. Therefore, its physical crosslinking can be destroyed under shear effect. Additionally, the hydrogel viscosity can be recovered after it is kept static for a while. Accordingly, it has a reversible transition behavior. This thixotropic property allows the supramolecular gel particles to gradually dissolve and release the drug through oral administration, which can achieve the goal of sustained release drugs in a period of time. These gel particles can also stabilize water-soluble compounds, especially for reducing the enzymatic hydrolysis of peptide compounds like the insulin, and are often used as the study of controlled release systems for water-soluble compounds $^{[38]}$.

Sibiya et al. wrapped human insulin using intestinal biodegradable galacturonic acid gel particles (pectininsulin, PI particles) and drenched diabetic mice. The results showed that PI particles not only released insulin persistently but also reduced the concentration of blood glucose with concentration-dependency. Moreover, this method also can protect the kidney during the oral application. Thus, it can be seen that this kind of hydrogel had a great prospect and it should encourage further evaluations and development in this method to make it into food administration ${ }^{[35]}$.

$\mathrm{Xu}$ et al. found that the hypoglycemic effect of P (MAA-g-EG) copolymer hydrogel containing insulin was significantly correlated to its dose. This $\mathrm{pH}$-sensitive hydrogel was expected to be used as a drug carrier ${ }^{[40]}$. Yamagata et al. studied the protection mechanism of this hydrogel. $\mathrm{P}(\mathrm{MAA}-\mathrm{g}-\mathrm{EG})$ hydrogels protected internal insulin by forming a copolymerization complex in gastric juice. In intestinal juice, the hydrogel can significantly reduce the degradation rate and the level of the calcium ion in insulin. The protection efficiency of insulin depended on the carboxyl fragment in polymers.

On the other hand, the degradation efficiency to inhibit insulin in intestinal juice was significantly correlated to calcium ion in this kind of hydrogel, suggesting that the loss of calcium ion played an important role in inhibiting the activity of intestinal enzyme. The results showed that 
P(MAA-g-EG) hydrogel can be a very good protective carrier in gastrointestinal absorption of insulin ${ }^{[41]}$.

Currently, hydroxyethyl methacrylate (HEMA), one low fouling material, was employed to produce one novel nanogel through microemulsion polymerization method. Compared to oral insulin administration, this special nanogel had both higher value of cumulative hypoglycemic effect and lower minimum blood glucose (nearly $50 \%$ of basal level), which can last for 12 hours $^{[45]}$. Thus, nanogel was proved to be an alternative way to delivery insulin via oral administration.

\section{Other method}

In recent years, EligenTM technology has brought up more and more attention. A compound with low molecular weight is used as carrier. The non-covalent interaction between this carrier and insulin is very weak. It can improve the lipophilicity of insulin and its ability to permeate gastrointestinal epithelium. EligenTM technology is a kind of macromolecule-delivering platform technology developed by Emisphere Technologies, Inc. Emisphere delivery agents, which are based on sodium $\mathrm{N}$-[8-(2-hydroxy-benzoyl)aminocaprylate] (SNAC), interact with the drug molecules to create a weak, noncovalent association. In this situation, the drug remaining chemically unmodified ${ }^{[46]}$. After loading of specific compounds in this way, they can be transported across the epithelial membrane ${ }^{[47]}$. The mechanism of this method is that due to the weak association between carriers and drugs, the interaction is reversible. In addition, drugs released are supposed to be in the therapeutically active state. Unlike the other traditional penetration enhancers, which may cause some damage to the intestinal epithelium once they penetrate through it, Emisphere delivery agents were purport to keep the intestinal epithelium intact when it goes through the intestinal epithelium and this delivery system are suitable to various groups of compounds whose molecular weight range from 500 to more than 150,000 Daltons. Consequently, this technique could be a potential method to deliver insulin and make it into food.

Starokadomskyy et al used N-[8-(2-hydroxybenzoyl) amino] caprylate (SNAC) as a carrier to study how insulin was absorbed by crossing caco- 2 monolayer cells. The results showed that SNAC could increase the permeability of insulin by about 10 times, without affecting the permeability of mannitol or damaging cytomembrane. It could also protect insulin from being degraded by protease $^{[48]}$. The feasibility of EligenTM technology for delivering insulin orally have been proved both in humans and animals. However, it does not mean that this tech- nology is perfect, since it may cause some consumer feel nausea. Thus, if researchers want to use this technology as food application, some specific corrigent is necessary ${ }^{[49-55]}$.

Interestingly, one new ingestible self-orienting system for oral delivery of insulin was developed. It was the first time that the injection method was involved in the oral delivery. Alex et al. developed a special pill called ingestible self-orienting millimeter-scale applicator (SOMA) that autonomously positioned itself to engage with GI tissue inspired by the leopard tortoise's ability to passively reorient. It then deployed milliposts fabricated from active pharmaceutical ingredients (insulin) directly through the gastric mucosa while avoiding perforation (Figure 3$)^{[56]}$. Inside the pill was a $7 \mathrm{~mm}$ long conical cylinder with a conical front end pressed by insulin. The conical front end was aligned with the pill in the direction of gastric mucosa. The cylindrical part under the cone was made of cellulose, and the bottom of the pill was supported by a compressed spring. The cylindrical body was filled with rapidly soluble sugars between the cylindrical body and the small hole. After the pill was standing in the gastric mucosa, the sugar dissolved as the pill got in contact with the gastric mucosa, which will cause a reduction of pressure at the conical front. As a result, the conical front containing insulin would be ejected by the spring that was relaxed due to the pressure difference. The conical front would then dissolve as well, followed by the releasing of insulin (Figure 3). By optimizing the shape and mass center of the pill, the gravity center of the pill was always outside the fulcrum as long as the bottom plane did not contact the surfaces of the gut, and finally stood on the surface of the gastric mucosa. Although the area of the gastric mucosa can be horizontal or moderately inclined, the pill can still stand on it by itself (Figure 3). As a result, when the blood concentration of insulin was more than 20 times lower than that of conventional injection, it was still enough to exert $40 \%$ hypoglycemic effect ${ }^{[56]}$. However, some weaknesses of this research should be mentioned. First, the blood sugar with the $40 \%$ reduction, in the research, referred to fasting blood sugar, which is often several times lower than postprandial blood sugar. That means that the absolute amount of insulin absorbed was not enough to control postprandial blood sugar, while the control of postprandial blood sugar, not basic blood sugar control, is more needed for non-injection insulin administration. Moreover, slow dissolution of the conical end would cause springs to be released slowly, , which might possibly lead to the elevation of the pills, especially in the case of inclining. 


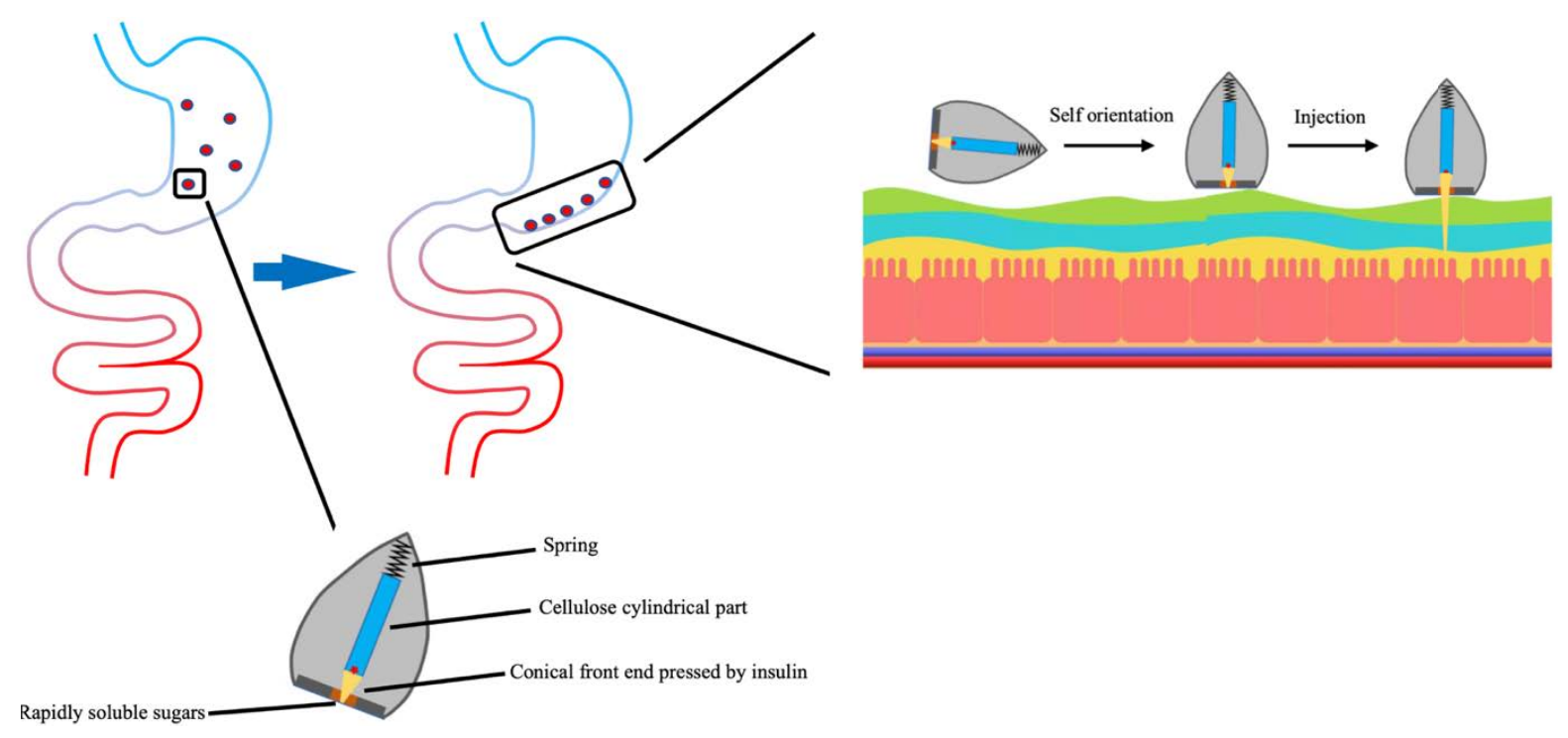

Figure 3. The mechanisms of ingestible self-orienting millimeter-scale applicator

\section{Materials used for encapsulation}

\subsection{Natural Polymeric materials}

Natural Polymeric nanoparticles are the nanoparticles made by natural materials. This kind of nanoparticles often has low toxicity. They are therefore used to encapsulate insulin recently (some of them are shown in Table 1). These materials are comprehensively introduced in this section.

\subsubsection{Chitosan-based materials}

Chitosan (CS) is a kind of polysaccharide consisting of partially deacetylated chitins. It is a polymer extracted from the shells of crustaceans and insects (shown in Figure 3$)^{[57]}$. The physical and chemical properties of CS are affected by relative molecular weight, deacetylation degree and the $\mathrm{pH}$. Since CS is positively charged and the mucous layer is negatively charged, CS is easily adsorbed mucosally and can prolong the retention time of drugs in small intestine ${ }^{[58]}$. Besides, CS can reversibly open tight junctions between Caco-2 monolayer cells (shown in Figure 4), reduce their transmembrane resistance and increase paracellular permeability ${ }^{[59]}$.

PA-CS prepared by Mukhopadhyay et al. was $\mathrm{pH}-$ sensitive and can make drugs invariant in the gastrointestinal tract. Following oral administration to diabetic mice at $50 \mathrm{IU} / \mathrm{kg}$, the relative bioavailability was $11.78 \%$. There was no severe systemic toxicity ${ }^{[60]}$. A type of $\mathrm{pH}$-sensitive nanoparticle, PMAA-CS-PEG, was used for oral delivery of insulin, as well. The entrapment efficiency of this nanoparticle was up to $99.9 \%$. The average particle size was $172 \mathrm{~nm}$. The release of insulin in the intestine was twice as much as that in the stom-

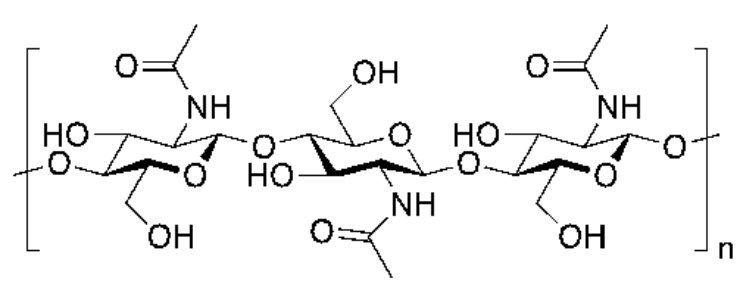

Chitin

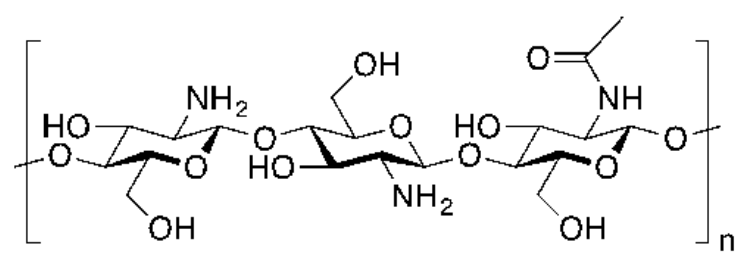

Chitosan

Figure 4. Chemical structures of chitin and chitosan
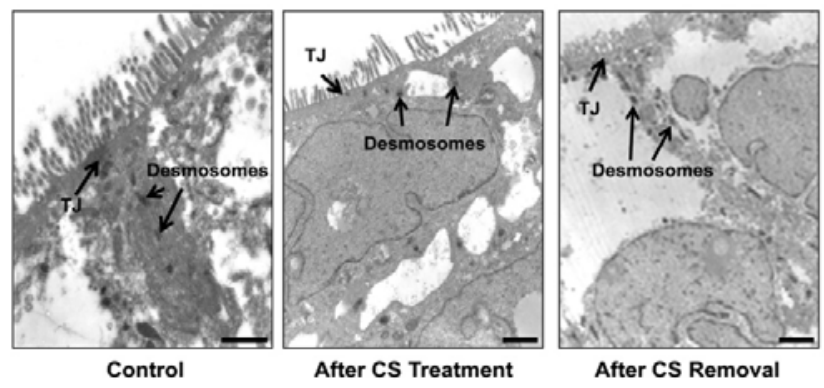

Figure 5. TEM micrographs of the polarized Caco-2cells before CS treatment (control), after CS treatment and following CS removal (scale bars: $0.5 \mathrm{~m})^{[59]}$ 
Table 1. Natural polymeric nanoparticles prep method, physical properties and results

\section{Preparation method}

Chitosan modified with valine by conjugating the terminal carboxy groups of carboxymethyl chitosan (CMCS) to the amino groups of 3-APBA and L-Valine to synthesize CMCS-PBA-LV

Insulin loaded into the nanocarrier

Polyelectrolyte complexation is formed between insulin and chitosan/pectin, without the usage of chemical crosslinkers.

Poly(3-methacrylamido phenylboronic acid) (PMAPBA) complexed with thiolated chitosan (chitosan-SH) forming cross-linked shell.

$240-300 \mathrm{~nm}$

Polyurethane (PU) is incorporated into shell of NPs with alginate (ALG) and chitosan (CS)

Insulin cross-linked with chitosan shell

dextran sulfate.

The dual coating was applied by polyelectrolyte complexation

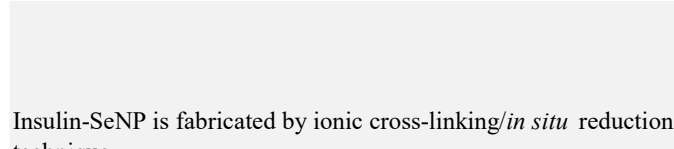
technique.

\section{Approximately 120 to $160 \mathrm{~nm}$ depending on different chitosan/insulin ratio, $\mathrm{pH}$ and $\mathrm{Se}$ concentration}

$293 \pm 4 \mathrm{~nm}(5 \mathrm{~min}$ ultrasonication + co surfactant)

Insulin complexed with nanoparticle matrix polymers, alginatedextran sulfate and the complex was $\mathrm{pH}$-stabilized due to electrostatic effect.

Insulin is first conjugated with LMWP, which then made into NPs through $\mathrm{W} / \mathrm{O} / \mathrm{W}$ double emulsion

$248 \pm 2 \mathrm{~nm}(10$ min + cosurfactant)

$253.8 \pm 6.4 \mathrm{~nm}$
Efficiency / in vitro observation / in vivo observation

Reference

EE: $67 \%$

LC: $9.8 \%$

Only a release of $16.6 \%$ in simulated gastric fluid

Production yield maximum: $34.0 \%$

EE highest: $62.0 \%$

Stable in simulated gastric fluid $(\mathrm{pH}=1.2)$

Controlled release over $2 \mathrm{~h}$ in simulated intestinal fluid $(\mathrm{pH}=6.8)$

EE: $50-64 \%$

LC: $13-19 \%$

In glucose-free medium, after $2 \mathrm{~h}$, release is $16 \%$ for PMAPBA1/chitosan-SH NPs, $51 \%$ for

PMAPBA1/chitosan NPs.

At $\mathrm{pH}=7.4$, Initial burst release observed in medium with different concentrations of glucose. Release after 9 $\mathrm{h}$ in $0,1.0$, and $3.0 \mathrm{mg} / \mathrm{mL}$ glucose concentration were 20,28 , and $97 \%$

EE: more than $90 \%$ insulin

At $\mathrm{pH}=1.2$, slight insulin release (PU-ALG/CS $13.7 \%$, ALG/CS $15.77 \%$ and PU-ALG $14.17 \%$ ) up to one hour Improved insulin bioavailability $(10.36 \%)$

Moderate release at $\mathrm{pH}=6.8$ for PU-ALG/CS NPs up to $50 \%$ at $10 \mathrm{~h}$, sustained release at $\mathrm{pH}=7.4$
$313.2 \pm 2.8 \mathrm{~nm}$ (ADS-NPs), 338.8

$\pm 5.8 \mathrm{~nm}(\mathrm{CS}-$

NPs), $300.8 \pm 3.8$ $\mathrm{nm}$ (ALB-NPs)
EE: $72.4 \pm 3.3 \%$ (ADS-NPs), $21.9 \pm 2.8 \%$ (CS-NPs) $30.7 \pm 3.4 \%$ (ALB-NPs)

DL: $10.1 \pm 2.8 \%$ (ADS-NPs), $4.8 \pm 0.4 \%$ (CS-NPs), 6.2 $\pm 1.4 \%$ (ALB-NPs)

Decrease in efficiency due to extra coating step

In $\mathrm{SGF}(\mathrm{pH}=1.2$ ), up to $35 \%$ release for $2 \mathrm{~h}$, in comparison to $80 \%$ for free insulin

Release only increased when raising $\mathrm{pH}$ from 5.5 to 7.4

Release was more sustained at $\mathrm{pH} 7.4$ than 5.5 for both CS-NPs and ALB-NPs

EE: around $80 \%$ for most types of particles

Insulin-SeNPs showed release of $30 \%$ within $12 \mathrm{~h}$ in both $\mathrm{pH} 1.2 \mathrm{HCl}$ solution and $\mathrm{pH}$ 6.8 PBS. However,

Insulin-SeNPs release was $55 \%$ in aerobic condition

Relative pharmacological bioavailability (PA) of INSSeNPs $(12.5 \mathrm{IU} / \mathrm{kg}$, oral) to insulin (1 IU $/ \mathrm{kg}$, s.c. $)$ was up to $9.15 \%$

EE: $99.3 \% \pm 0.5 \%$

In $\mathrm{SGF}$ ( $\mathrm{pH}=1.2$ ), bare release during the first 2 hours, followed by a burst release of insulin was noticed under basic conditions ( $\mathrm{pH}$ 6.8) simulating the intestinal environment

Release almost finished in the following 3 hours

EE: $49.3 \pm 2.1 \%$

DL: $8.2 \pm 0.4 \%$

Burst release within $1 \mathrm{~h}$ followed by slow release until $6 \mathrm{~h}$.

$\mathrm{P}_{\mathrm{app}}$ value of insulin loaded in NPs treated with LMWP treatment. 
$\mathrm{ach}^{[61]}$. Su et al. prepared DTPA- PGA-CS nanoparticles. When $\mathrm{pH}$ was greater than seven, the nanoparticles gradually expanded and degraded. By opening the tight junction between intestinal epithelial cells, the absorption of insulin in small intestine can be promoted with prolong hypoglycemic duration ${ }^{[62]}$.

\subsubsection{Chitosan derivative based materials}

The PKa value of CS is about 6.5 , and the deprotonated form of CS is insoluble in neutral or alkaline environment. At a pH of 7.4, CS will lose mucus adsorption and the ability to open tight junctions ${ }^{[63]}$. The physical and chemical properties of CS, such as water solubility, mucus adsorption and intestinal permeability can be enhanced to some extent by chemical modifications. Several CS derivatives have been synthesized and prepared, including trimethyl CS (TMC), sulfhydryl CS and $\beta$-cyclodextrin-CS.

Methyl was introduced to CS to make TMC, to improve the solubility of CS in neutral or alkaline environments. By modifying TMC using a targeting polypeptide-CSK polypeptide, we can get CSK-TMCinsulin nanoparticles. Compared with unmodified TMCinsulin nanoparticles, they had lower cell toxicity. Since CSK and intestinal goblet cells have a very good affinity, namely, CSK-TMC nanoparticles are targeted at goblet cells, they can improve the permeability of nanoparticles in the small intestine. In a hypoglycemic experiment, following oral administration of CSK-TMC nanoparticles to diabetes rats $(50 \mathrm{IU} / \mathrm{kg})$, the blood glucose level fell by $28 \%$ within $3 \mathrm{~h}, 1.4$ times as fast as TMC nanoparticles, and the relative bioavailability was 1.5 times as high as TMC nanoparticles ${ }^{[64]}$. Liu et al. prepared trimethyl CS nanoparticles (T-NPs) and made trimethyl $\mathrm{CS}$ nanoparticles (P-T-NPs) using water-soluble poly (N2 hydroxypropyl methacrylate) as the coating material. Compared with the former, the latter had good mucosa permeability and can better open tight junctions between cells and promote the transcellular transport of nanoparticles. 4 hours after oral administration of P-T-NPs to diabetic rats $(50 \mathrm{IU} / \mathrm{kg}$ ), the blood glucose concentration fell by $36 \%$. The hypoglycemic effect was significantly higher than the same dose of T-NPs. There was no hypoglycemia. The bioavailability was 2.8 times that of T-NPs ${ }^{[65]}$.

Mercaptide polymer possesses a mercapto structure and is absorbed via mucous. It can form sulfhydryl disulfide with mucin, closely attached to the mucous layer of the small intestine and prolong the effect of insulin. Besides, mercaptide can enhance permeability by inhibiting protein tyrosine phosphatase ${ }^{[66]}$. Yin et al. prepared N-trimethyl chitosan-cysteine nanoparticles (TMC-CysNPs) (the synthetic route of self-assembled
TMC-CysNP are shown in Figure 5), forming disulfide bonds with the mucous layer. Therefore, mucous adsorption of TMC-CysNP was $2.1 \sim 4.7$ times as high as that of TMCNPs. During the in vivo studies, TMCCysNPs can better promote the permeability of insulin in the small intestine of rats and prolong hypoglycemic duration $^{[67]}$.

Cyclodextrin-insulin compounds can protect insulin from aggregating, degrading and denaturing and make it exist stably. By lowering biological barrier function, researchers can promote the absorption of insulin ${ }^{[68]}$. However, cyclodextrin matrix has renal toxicity and poor water solubility, which restricts its role as a pharmaceutical preparation. Researchers can overcome the above problems by preparing cyclodextrin derivatives, such as sulfobutyl- $\beta$-cyclodextrin and hydroxypropyl- $\beta$ cyclodextrin. Zhang et al. prepared positively charged $\beta$-cyclodextrin-modified CS nanoparticles. The entrapment efficiency was $87 \%$. Since insulin mainly existed in the chitosan-alginate nucleus and had electrostatic interactions with -cyclodextrin, it wouldn't degrade in intestinal juice ${ }^{[69]}$.

\subsubsection{Dextran-based materials}

Dextran is a good carrier for entrapping protein and can provide a stable environment with biocompatibility. The bioactivity of insulin can be maintained during the preparation of nanoparticles and the release of insulin. Besides, the bioactive components in dextran directly combine with targeting ligands, therefore, can solve the poor permeability of polypeptide and protein. In order to further improve the absorption of nanoparticles in the gastrointestinal tract, Chalasani et al made dextran and epichlorohydrin into nanoparticles by means of emulsification and cross-linking. The surface of nanoparticles was modified with succinum glycoside and combined with VB12. The nanoparticles can protect $65 \% 83 \%$ of insulin from being destroyed by intestinal protease ${ }^{[70]}$. Other Reis et al. found that entrapping insulin with alginate-dextran can inhibit the release of insulin in acidic conditions and increase release in neutral conditions and demonstrated that nanoparticle-entrapped insulin had bioactivity using both in vivo and in vitro bioassays ${ }^{[71]}$. Zhenqing et al. prepared insulin into Insulinloaded Sanguis Draxonis nanocapsules (ISDN) using deposition technology. The stability test showed that the activity of most of the insulin in ISDN not only sustained in a solution containing proteolytic enzyme at $37^{\circ} \mathrm{C}$ for 30 minutes but also sustained at $25^{\circ} \mathrm{C}$ for 6 months. The ISDN was administered to diabetic mice by 25,50 and $75 \mathrm{ug} / \mathrm{kg}$. Eight hours later, the level of blood glucose fell to $(60.5 \pm 2.7) \%,(52.6 \pm 2.3) \%$ and $(47.3 \pm 3.1)$ $\%$ that of the level before the administration. Addition- 

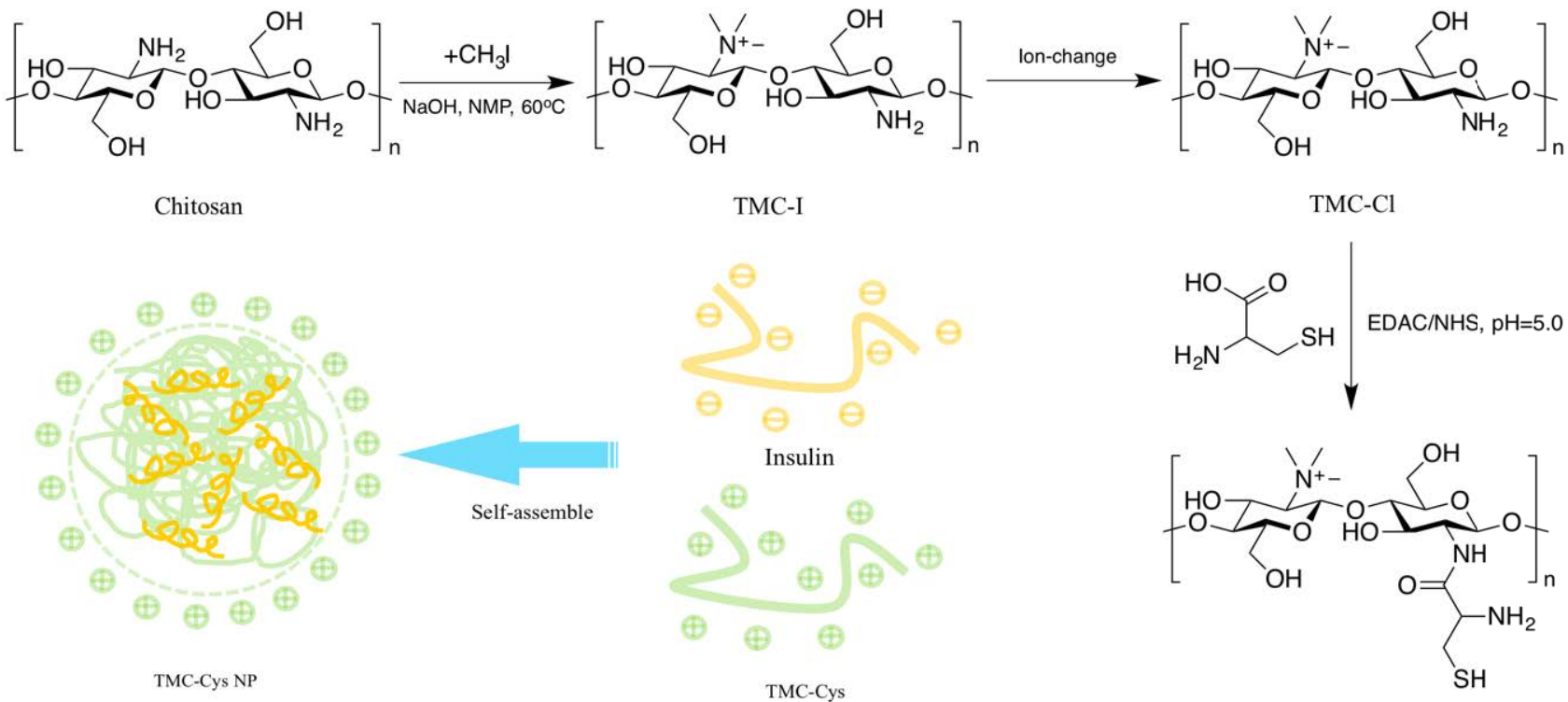

TMC-Cys

Figure 6. Synthetic route of TMC-Cys and representation of the formation of self-assembled TMC-Cys NP

ally, the reducing effect of blood glucose could last 2 to 4 days, suggesting that ISDN was a stable and effective delivery system of insulin ${ }^{[72]}$.

Recently, fatty acids and cholic acid were also used to produce chitosan derivative based nanoparticles. Cholic acid modified N-(2-hydroxy)-propyl3-trimethylammonium chitosan chloride (HTCC) was reacted with lauric acid (LA) and oleic acid (OA) through the amidation reaction to produce HTCC-LA and HTCC-OA. The nanoparticles were produced by the electrostatic and hydrophobic interactions between insulin and the HTCC-LA and HTCC-OA. The particle size was about $280 \mathrm{~nm}$ with $98 \%$ entrapment efficiency. After they were administrated by diabetic mice, the bioavailability of insulin increased $233 \%$ and $311 \%$ compared with free insulin group. The results showed that fatty acid-modified chitosan could also be an effective delivery system of insulin ${ }^{[73]}$. The other novel chitosan derivative based nanoparticles was produced by enterohepatic circulation of bile acids and quaternary ammonium modified chitosan derivative and hydroxypropyl methylcellulose phthalate (HPMCP). The particle size of this kind of nanoparticles was $239 \mathrm{~nm}$ with loading efficiency of $90.9 \%$. The in-vivo test showed that the hypoglycemic effect can last for more than 24 hours and their bioavailability was $30 \%$ even compared with injection $^{[74]}$. These results showed that more novel compounds can be selected to modify chitosan to achieve effective delivery systems of insulin.

\subsubsection{Starch-based materials}

As a type of naturally biodegradable renewable resource, starch is non-toxic, widely-sourced, nonimmunogenic, stable in air and compatible with most drugs. It is widely applied in the pharmaceutical field. But some of its inherent characteristics greatly limit its application, such as insolubility in cold water, the instability of starch paste and the tendency of aging and aging under heat, acid and shear action, poor film-forming property and transparency and poor freeze-thaw stability, etc. Therefore, it is necessary to modify the original starch to improve its structure and property, promote its function and expand the application scope ${ }^{[75]}$. Using starch nanoparticles as the backbone and polyglutamic acid as the branch chain, Zhang et al. made a new oral delivery system of protein drugs (SNP-g-PGA). SNP-gPGA is pH-sensitive and has good stability in acid conditions $^{[76]}$.

\subsubsection{Silica-based materials}

Silicon is used to entrap insulin because of its porosity, strong absorbability, superior permeability and slow release, etc. Mesoporous silica nanoparticles (MSNs) have good biocompatibility and cellular internalization. An in vivo experiment showed that these nanoparticles can improve the permeability of insulin in ileal villus, thereby lowering the blood glucose level ${ }^{[77]}$. Zhao et al. prepared silica nanoparticles coated by hydroxypropyl methylcellulose phthalate (Ins-SiO2-HP55). Following oral administration to diabetic rats (30 IU $/ \mathrm{kg}$ ), the blood glucose level remained at levels of $4.85 \sim 2.67 \mathrm{mmol} / \mathrm{L}$, 
significantly lower than the normal level ${ }^{[78]}$. Considering the function of pure silica is single, Lee et al may combine it with the functional polymer or small organic molecules using physical or chemical methods in order to promote the functionality and specificity of functional and intelligent nanoparticles ${ }^{[79]}$.

\subsubsection{Tragacanth-based materials}

Biopolymers such as tragacanth, an anionic polysaccharide gum, can be a kind of alternative polymeric carrier for physiologically important peptides and proteins. It can form a polyelectrolyte complex with the insulin-like the chitosan-based nanoparticles. However, current research found the tragacanth-based nanoparticles showed better mucoadhesion than chitosan-based nanoparticles. In addition, Its stability also cannot be affected by the temperature and shearing ${ }^{[80]}$. Therefore, tragacanth-based nanoparticles can be a potential method to encapsulate the insulin.

\subsection{Synthetic polymeric materials}

Fabrication methods associated with nanoparticles made with synthetic polymers are usually double emulsion-solvent evaporation method brought up above. The recent trend of development is to add modifications of nanoparticles, in order to improve encapsulation efficiency, release profile or cell permeability, etc. Lal et al. applied montmorillonite (Mt) as organic layer of emulsion, which is not only non-toxic and bio-inert itself, but also show excellent adsorption properties of toxins sourced from diet, bacteria, etc. ${ }^{[81]}$ Optimal formulation processes high encapsulation efficiency and decreased burst release in more sustainable ways. Cell-penetrating peptides (R8, Tat and penetratin) and secretion peptide were studied by Zhu et al., and the resulting nanoparticles are proved to have greater permeability with the additional use of secretion peptide compared to penetratin alone ${ }^{[82]}$. Liu et al. modified nanoparticles with targeting ligand FQSIYPpIK (FQS), by coating FQS modified trimethyl chitosan chloride to cores of insulin-loaded micelles $^{[83]}$. In the experiment performed by Sun et al., the nanoparticles initially prepared are of no difference from emulsion-solvent evaporation method, achieving PLGA coated nanoparticles, which then were further encapsulated into $\mathrm{pH}$-sensitive hydroxypropyl methylcellulose phthalate (HP55) by spray drying method ${ }^{[84]}$.

\subsubsection{Inert polymers}

Due to the destruction and degradation of insulin in the digestive tract, one of the major challenges of encapsulation it is to overcome the gastrointestinal barriers. The best way to do this is via encapsulating insulin with enteric capsules (using spray-drying for example) or turning them into pellets for oral use. Inert polymer

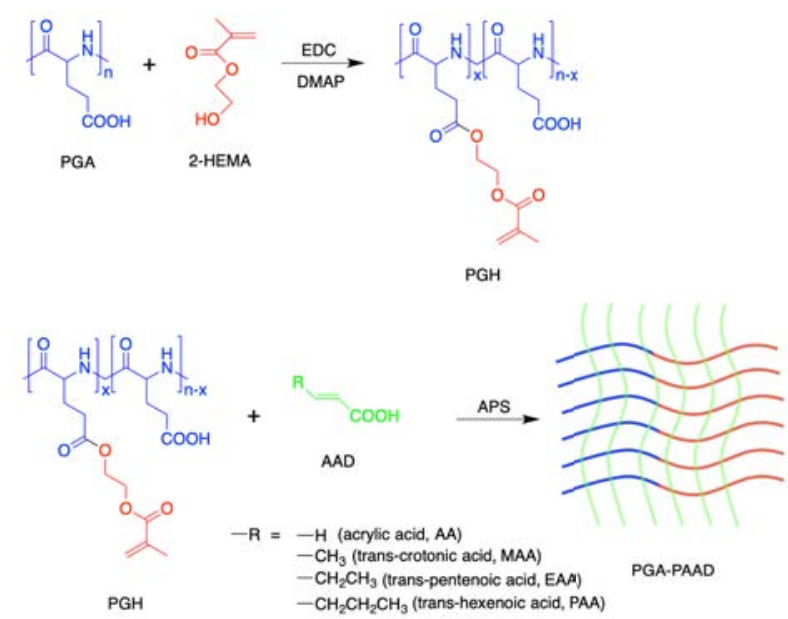

Figure 7. The structure of PGA-PAAD

materials with polyacrylic acid and its ester derivatives (PAAD) have evolved as good candidates for the coating material. The carboxylic groups in PAAD could be a potential inhibitor of some proteolytic enzymes responsible for insulin degradation in GI tract by binding to available calcium ions $\left(\mathrm{Ca}^{2+}\right)$ critical to the degrading action of these enzymes ${ }^{[55]}$. Moreover, this group renders enteric properties to such coatings (i.e. protection of insulin in stomach's acidic environment, releasing them under low acid conditions in the small intestine). PAAD is stable in acid environment such as the stomach, followed by releasing insulin into small intestine, which makes itself an appealing candidate for encapsulation ${ }^{[86]}$. The amount of coating materials used and their effect on the rate of drug release are also inconsistent among different studies. Besides, permeation performance varies among different inert polymer materials. Thus, it is necessary to design a specific PAAD that can deliver insulin properly.

PAAD has been used for encapsulation of insulin by many groups ${ }^{[86-88]}$. Gao et al have developed a specific hydrogel made by 4 types of PAAD together with a kind of poly-glutamic acid (PGA) (shown in Figure 6) to control the release of insulin to targets. In vitro test indicated that the release rate of insulin was quite lower in $\operatorname{AGF}(\mathrm{pH}=1.2)$ in the presence of pepsin. By contrast, insulin can be steadily released in AIF $(\mathrm{pH}=6.8)$ in the presence of pancreatin. In vivo test showed that after diabetic rats were given insulin-loaded by this material, the hypoglycemic effect was ameliorated and could last for 7 hours $^{[87]}$

In addition, Zhang et al. raised another special PAAD called CMC-g-PAA (Carboxymethyl chitosan-gpolyacrylic acid). In in vitro test, the result also showed it was very stable in acid condition and could release insulin in neutral environment (shown in Figure 7). The in 
vivo test showed that after the diabetes mice were administered with $100.0 \mathrm{IU} / \mathrm{kg}$ of insulin-loaded-CMC-g-PAA hydrogel, their blood glucose decreased by $34.1 \pm 4.7 \%$ and the effect could last for about 9 hours, which was longer than the previous one ${ }^{[88]}$. Thus, this material can be a potential encapsulating material for insulin and can potentially play a leading role to make insulin into some food products.

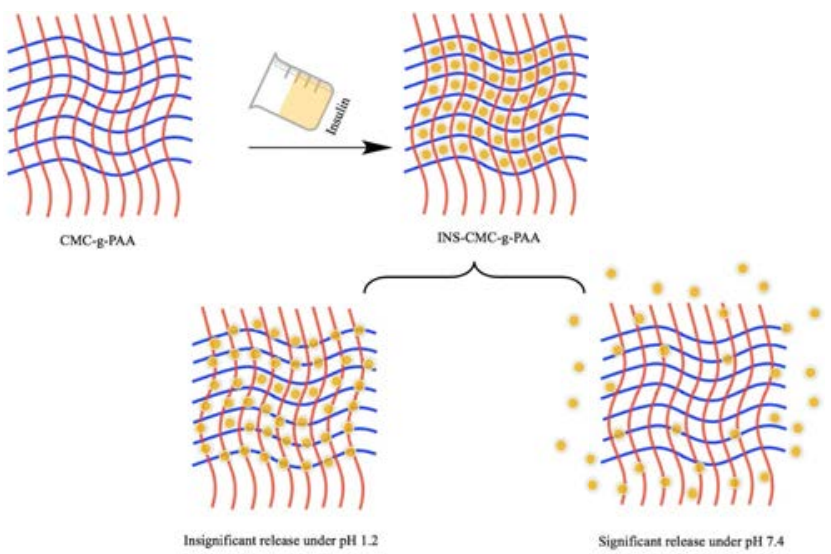

Figure 8. The result of the in vitro test of the CMC-g-PAA

\subsubsection{PLGA}

Poly (lactic-co-glycolic acid) (PLGA) is polymerized by lactide (LA) and glycolide (GA) and widely studied in terms of oral insulin preparations. Modification of PLGA nanoparticles with cell penetrating peptides and secrete peptides can help insulin permeate intestinal epithelial cells, thus improves its bioavailability. Research on PLGA nanoparticles suggested that PLGA nanoparticles had uniform sizes and high entrapment efficiency. Burst release could be reduced as well. After Diabetic rats were given PLGA nanoparticles at $10 \mathrm{IU} / \mathrm{kg}$, their blood glucose fell more significantly within $14 \sim 16$ hours than those taking uncoated nanoparticles ${ }^{[82]}$. Intestinal epithelial cells contain lots of folate (FA) receptors. The particle size of specific PLGA nanoparticles (FA-PEG-PLGA nanoparticles) prepared by Jain et al using multiple emulsion solvent evaporation was 260 $\mathrm{nm}$. The entrapment efficiency was $(87.0 \pm 1.92) \%$. Compared with the subcutaneous injection of insulin solution, oral administration (50 IU/kg) would not cause as much hypoglycemic shock to diabetic rats. The hypoglycemic duration was about 3 times that of subcutaneous injection. Compared with PEG-PLGA nanoparticles, it had better hypoglycemic effect ${ }^{[89]}$. Additionally, Malathi et al. prepared natural water-soluble VE and PLGA nanoparticles coated with emulsified polyethylene glycol (TPPLG nanoparticles). The maximum entrapment efficiency was $(78.6 \pm 1.2) \%$. After taking PLGA (70/30) nanoparticles, blood glucose level fell at a rate of 3 times as in the case of oral insulin solution. As reported by histopathological studies, TPPLG nanoparticles could recover damages to liver, kidney and pancreas caused by streptozotocin, suggesting that nanoparticles had both biocompatibility and repair effect ${ }^{[90]}$.

However, depending on the different synthetic process, the relative molecular weight of PLGA and molar ratios of LA and GA differ from each other as well. By changing the ratios of LA and GA, degradation of polymer and subsequent release rate of drug in vivo can be controlled. The metabolites of PLGA in vivo are $\mathrm{CO}_{2}$ and water, which are non-toxic and non-irritant and have good biodegradability ${ }^{[91]}$.

\subsubsection{PolyLactic Acid (PLA)}

PLA Vesicles are a special kind of nanoparticle with a bilayer structure. It can entrap both hydrophobic and hydrophilic drugs and control drug release effectively, so as to achieve the purpose of sustained release. Xiong et al synthesized two kinds of bilayer vesicles, which were hydrophilic inside and hydrophobic outside. The first kind of the bilayer vesicle was taking PLA-F127PLA (the formula and the synthetic route of PLA-F127PLA is shown in Figure 8) as a carrier of insulin. The in vivo experiment found that within $4.5 \mathrm{~h}$, the blood glucose concentration fell from $18.5 \mathrm{mmol} / \mathrm{L}$ to $5.3 \mathrm{mmol} / \mathrm{L}$. Five hours later, the blood glucose concentration was at the minimum level of $4.5 \mathrm{mmol} / \mathrm{L}$ and remained for at least 18 hours $^{[92]}$. The other kind, PLA-P85-PLA, was synthesized (the formula and the synthetic route of PLAP85-PLA is shown in Figure 8) as a carrier of insulin. An in vitro release experiment showed that after 7.5 hours of administration, insulin was completely released. Following oral administration to diabetic mice $(200 \mathrm{IU} / \mathrm{kg})$, the blood glucose concentration reached the minimum level, $15 \%$ of the original blood glucose concentration in 2.5 hours. 10.5 hours later, it rose to $31 \%$ of the original and remained at this level for about 14 hours ${ }^{[93]}$. Chen et al prepared insulin polylactic acid nanoparticles (INSPLA-NPs) by 'solvent-nonsolvent' method. The average particle size was $(84.34 \pm 14.76) \mathrm{nm}$. The average coating rate was $(65.93 \pm 13.45) \%$. The average drug loading rate was $(0.62 \pm 10.03) \mathrm{U} / \mathrm{mg}$. After INS-PLANPs were administered to diabetic mice at 50,60 and $80 \mathrm{IU} / \mathrm{kg}$ respectively, their blood glucose all fell significantly ${ }^{[94]}$. Therefore, with respect to blood glucose level control, different PLA vesicles have an impact and can be used as a potential encapsulation method for oral intake. Similar to PLGA, the in vivo mesostate of PLA is lactic acid and the metabolites are $\mathrm{CO}_{2}$ and water. It shows good biodegradability. However, the high number of ester bonds in PLA worsen its hydrophilicity and lowers biocompatibility. Immune rejection is another con- 
cern, resulting in inflammation and infection, followed by thrombosis and even lesions ${ }^{[95]}$.
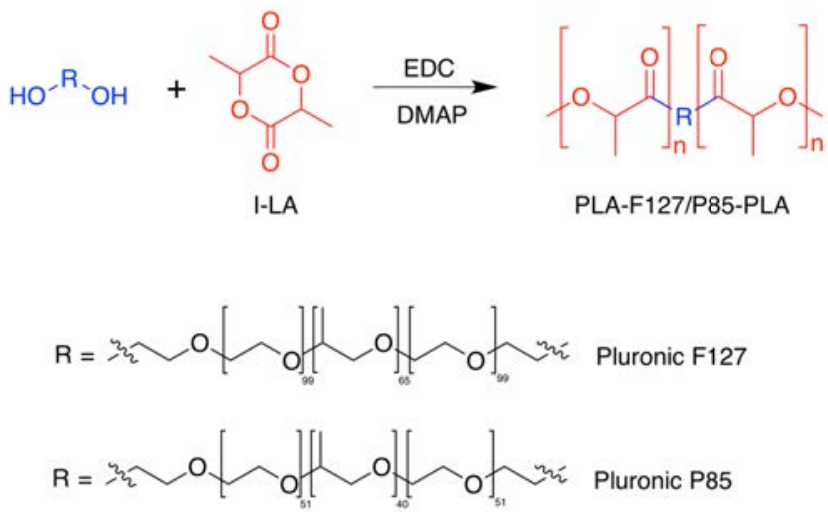

Figure 9. Molecular Formulas and synthetic routes of PLAF127-PLA and PLA-P85-PLA

\subsection{Solid lipid materials}

Using solid phase lipid as the oil phase, the entrapment efficiency of solid lipid nanoparticles was proved to be lower compared to polymeric nanoparticles, as shown in the Table 2 below. This is due to the hydrophobic nature of the lipid ${ }^{[96]}$. Double emulsion-solvent evaporation is the technique mostly used in solid lipid nanoparticles.

\section{Absorption mechanisms of different encap- sulation methods}

The goal of all the methods (nano-emulsions, multiple emulsions, liposomes and nanogels) is to safely transport insulin through the stomach, help it to intactly penetrate through the intestinal mucosa and epithelial cells and release it into the blood (Figure 10). Thus, they are more efficacious ways to deliver insulin compared with other oral consumption. Compared with other methods, multiple emulsions have a two-step release mechanism. They can first release the inner small particles after they go through the stomach and then the insulin can be carried by the small particle to penetrate the intestinal layers and released into the blood (Figure 10) ${ }^{[83]}$. For liposomes, an additional releasing behavior should also be mentioned. As the lipid bilayer of liposomes can fuse with other bilayers such as cell membrane, it can fuse to the cell membrane and the insulin can be endocytosed by the cell directly (Figure 10).

\section{Additional in-vivo test results of most re- cent research with highlights}

Various efforts have been made in order to enhance the hypoglycemic effect. This is often achieved by slight
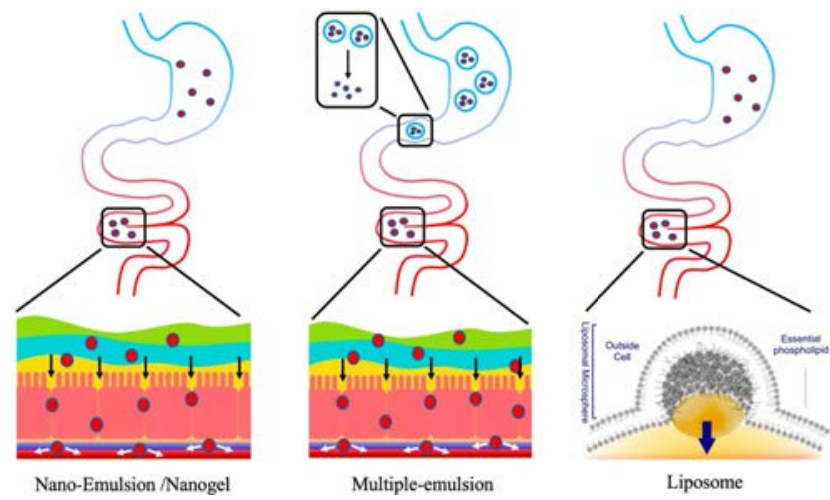

Figure 10. Absorption mechanisms of different encapsulation techniques

modification of the structure of natural polymers used in polymeric nanoparticles or the core of solid lipid nanoparticles. Hypoglycemic effect is most often illustrated by bioavailability or pharmacological availability (PA). Being supplementary to the in vivo test results incorporated above, in this section, a brief overview is provided in light of structural characteristics, permeability tests in monolayer caco- 2 cells where applicable, as well as test results in vivo.

L-Valine was incorporated into chitosan-based nanoparticles in order to facilitate the absorption at the site of small intestine and the relative pharmacological availability was found to be much higher with a value of $7.55 \pm 1.32 \%$ compared to that of free insulin (less than $0.8 \%)^{[82]}$. The combination of $\mathrm{N}$-trimethylated chitosan (TMC) and N-(2-hydroxypropyl) methacrylamide (HPMA) polymer (pHPMA) derivative could promote the mucosal adhesiveness and permeability at the same time, giving final bioavailability as high as $8.56 \%{ }^{[65]}$. Chitosan nanoparticles with trans-activating transcriptional peptide (Tat), a cell-penetrating peptide being incorporated, had hypoglycemic effect of 6.89 and 1.79 times higher than that of PVA-NPs and CS-NPs respectively. Moreover, it was worth noticing that this type of nanoparticles can reach the colon with an ideal physiological environment for absorption ${ }^{[82]}$. Another study relevant to Tat showed 3, 4, 2.16 and 1.73 folds for cellular transport, cellular uptake, pharmacological availability and bioavailability was achieved respectively for Eudragit S100 (ES)-Tat-chitosan nanoparticles, compared to nanoparticles with ES coating only. It was also worth noticing from the in vivo test that maximum hypoglycemic effect was achieved at 4 hours at level of $66.06 \%$, which lasted for 12 hours ${ }^{[101]}$. $\mathrm{N}$-(2-hydroxy)-propyl-3-trimethylammonium chloride modified chitosan (HTCC-CA)) nanoparticles, targeting liver, could achieve a time as long as 2-11 hours is 
Table 2. Solid lipid nanoparticles prep method, physical properties and results in vitro

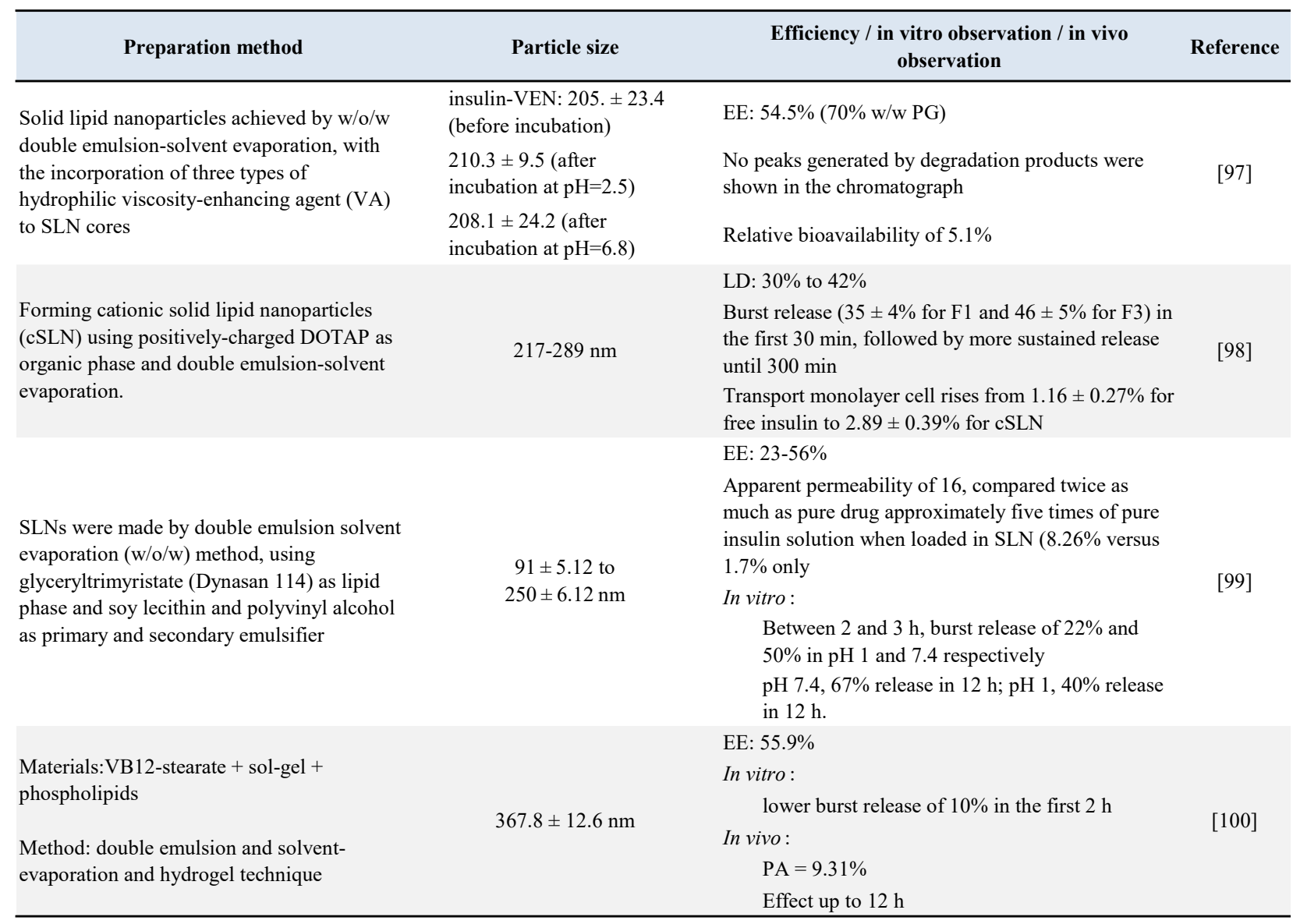

obtained for maintaining blood glucose level of lower than $70 \%{ }^{[102]}$. Folic acid was also used for enhancing cell permeability by promoting endocytosis. Blood glucose level of $50 \%$ of the initial is maintained for 12 hours with the bioavailability of $7.77 \%$ and pharmacological availability of $7.22 \%$ being obtained ${ }^{[103]}$. The use of hydroxypropyl- $\beta$-cyclodextrin on chitosan nanoparticles could achieve bioavailability of $20.32 \%$, due to the protective effect of hydroxyl and carboxyl group. However, the lowering of blood glucose level was not at high extent, though it could be maintained for 6 hours $^{[104]}$. Mediated by SAR6EW, a novel cellpenetrating peptide, the cellular uptake was greatly improved, the blood glucose level dropped to $49.3 \%$ in 3 hours and maintained at level of $81.6 \%$ for more than 8 hours $^{[105]}$. With deoxycholic acid modification of the chitosan nanoparticles, the relative bioavailability rose from $7.2 \%$ to $15.9 \%$ by exploiting bile acid pathway. The hypoglycemic effect lasted for up to 12 hours with a constant decrease in blood glucose level to about 50\% of the original ${ }^{[106]}$. The incorporation of cysteine or cell penetrating peptide exhibited 17 and 12 permeability across intestinal cells, with 1.86 to 2.03 relative bioavailability ${ }^{[53]}$. Insulin loaded alginic acid nanoparticles could increase the blood flow at site of action, with the bioavailability of $20.2 \%^{[107]}$. The application of dextran-b-poly(lactide-co-glycolide) polymersome also enhanced adhesiveness to GI tract, with permeability proved to be $16.89 \%$ and $9.34 \%$ for two types of DEX nanoparticles. Hypoglycemic effect also lasted for more than 12 hours, with blood glucose level decreased to a quarter of the original level ${ }^{[108]}$.

Similar modifications have also been applied to solid lipid nanoparticles. Viscosity-enhancing agents have been applied to solid lipid nanoparticle core. This was mainly to enhance encapsulation efficiency by preventing drugs from going to the aqueous phase. Concerning bioavailability, there was not much effect ${ }^{[97]}$. The development of cationic solid lipid nanoparticle using cationic lipid for better bioadhesion properties ${ }^{[98]}$. Another study employing glyceryltrimyristate (Dynasan 114) as lipid phase and soy lecithin and polyvinyl alcohol as primary and secondary emulsifier could produce nanoparticles with 5 times relative bioavailability $(8.26 \%)$ of that for 
free insulin $(1.7 \%)^{[109]}$. Vitamin B12 could be used to promote transport efficiency across the membrane, and therefore Vitamin B12 coated solid lipid nanoparticles could achieve pharmaceutical availability of $9.31 \%{ }^{[110]}$.

\section{Conclusions and Future Trends}

In recent years, research on insulin encapsulation is becoming more and more mature for oral consumption. As the encapsulation methods can protect the insulin from the enzymes and acid condition, the bioavailability of the insulin can be maintained through the gastrointestinal route. With the improvement of the carrier materials, the sorbefacient and the preparative methods, the bioavailability of insulin's oral preparations is increasing so that there is a higher likelihood of oral delivery. However, related issues still exist, which hinders it from being ideal for consumption: (1) in the preparation and storage of the oral insulin, how to maintain the physiological activity of it, especially for the storage process? (2) how to further reduce the inactivating effects of the digestive enzyme and the first-pass effect? (3) how to stabilize the configuration of insulin, which can reduce the multimerization of insulin molecular to promote the absorption of insulin in the intestine? Currently, insulin encapsulation is focused on inert polymer materials, some different kinds of nanoparticles, various emulsions, gel particle, liposomes and some other technologies. Taking this into consideration, some specific nanoparticles, the $\mathrm{pH}$ sensitive hydrosol and the EligenTM technology seems to be the more promising methods to encapsulate insulin effectively. If appropriate absorbefacients, crosslinking agents and enzyme inhibitors are selected in the combination of control of the accurate release time, targeting location and the duration time of insulin, bioavailability will certainly be improved, which is a key factor for optimal encapsulation of insulin for oral delivery. Besides, encapasulated insulin can also be used for buccal mucosal administration. The particle size of the them are small, and the contact area with the mucosa is large, which is favorable for rapid release and absorption ${ }^{[111]}$. What's more, the self-orienting millimeter-scale applicator (SOMA) proved the feasibility of the combination of the oral delivery and the injection method. This is perhaps the future of insulin oral delivery.

\section{References}

[1] Nur M and Vasiljevic T. Can natural polymers assist in delivering insulin orally? International Journal of Biological Macromolecules, 2017, 103: 889-901. https://doi.org/10.1016/j.ijbiomac.2017.05.138

[2] McGurk S. Ganong's Review of Medical Physiology 23rd edition Kim E Barratt Ganong's Review of Medi- cal Physiology - 23rd editionet al -McGraw Hill Medical-726pp-41.99978 00716056700071605673 . Nursing Standard, 2010, 24: 30-30. https://doi.org/10.7748/ns.24.20.30.s35

[3] Ramesan RM and Sharma CP. Challenges and advances in nanoparticle-based oral insulin delivery. Expert Review of Medical Devices, 2009, 6: 665-676. https://doi.org/10.1586/erd.09.43

[4] Kitabchi AE, Umpierrez GE, Miles JM, et al. Hyperglycemic crises in adult patients with diabetes. Diabetes Care, 2009, 32: 1335-1343. https://doi.org/10.2337/dc09-9032

[5] Petzold A, Solimena M and Knoch KP. Mechanisms of Beta Cell Dysfunction Associated With Viral Infection. Current Diabetes Reports, 2015, 15: 857. https://doi.org/10.1007/s11892-015-0654-x

[6] Hu EA, Pan A, Malik V, et al. White rice consumption and risk of type 2 diabetes: meta-analysis and systematic review. Bmj, 2012, 344: e1454-e1454. https://doi.org/10.1136/bmj.e1454

[7] Wild S, Roglic G, Green A, et al. Global prevalence of diabetes: estimates for the year 2000 and projections for 2030 . Diabetes Care, 2004, 27: 1047-1053. https://doi.org/10.2337/diacare.27.5.1047

[8] Ogurtsova K, Guariguata L, Whiting D, et al. Incorporating uncertainty measurement in the International Diabetes Federation Diabetes Atlas methodology for estimating global and national prevalence of diabetes in adults. Archives of Public Health, 2015, 73: 31. https://doi.org/10.1186/2049-3258-73-S1-P31

[9] Damg C, Reis CP and Maincent P. Nanoparticle strategies for the oral delivery of insulin. Expert Opinion on Drug Delivery, 2007, 5: 45-68. https://doi.org/10.1517/17425247.5.1.45

[10] Sonksen P and Sonksen J. Insulin: understanding its action in health and disease. British Journal of Anaesthesia, 2000, 85: 69-79. https://doi.org/10.1093/bja/85.1.69

[11] Heinemann L, Fleming GA, Petrie JR, et al. Insulin Pump Risks and Benefits: A Clinical Appraisal of Pump Safety Standards, Adverse Event Reporting, and Research Needs: A Joint Statement of the European Association for the Study of Diabetes and the American Diabetes Association Diabetes Technology Working Group. Diabetes Care, 2015, 38: dc150168-722. https://doi.org/10.2337/dc15-0168

[12] Park K, Kwon IC and Park K. Oral protein delivery: Current status and future prospect. Reactive and Functional Polymers, 2011, 71: 280-287. https://doi.org/10.1016/j.reactfunctpolym.2010.10.002

[13] Maianti JP, McFedries A, Foda ZH, et al. Anti-diabetic activity of insulin-degrading enzyme inhibitors mediated by multiple hormones. Nature, 2014, 511: 94-98. https://doi.org/10.1038/nature13297

[14] Zhang H, Huang X, Mi J, et al. Improvement of pulmonary absorptions of poorly absorbable drugs using Gelucire 44/14 as an absorption enhancer. Journal of Pharmacy and Pharmacology, 2014, 66: 1410-1420. https://doi.org/10.1111/jphp.12274 
[15] ilek A, elebi N and Tirnaksiz F. Lecithin-Based Microemulsion of a Peptide for Oral Administration: Preparation, Characterization, and Physical Stability of the Formulation. Drug Delivery, 2008, 13: 19-24. https://doi.org/10.1080/10717540500313109

[16] Jain D, Panda AK and Majumdar DK. Eudragit S100 entrapped insulin microspheres for oral delivery. AAPS PharmSciTech, 2005, 6: E100-E107. https://doi.org/10.1208/pt060116

[17] Barbari GR, Dorkoosh F, Amini M, et al. A novel nanoemulsion-based method to produce ultrasmall, waterdispersible nanoparticles from chitosan, surface modified with cell-penetrating peptide for oral delivery of proteins and peptides. International Journal of Nanomedicine, 2017, 12: 3471-3483. https://doi.org/10.2147/IJN.S116063

[18] Giri TK, Choudhary C, Ajazuddin, et al. Prospects of pharmaceuticals and biopharmaceuticals loaded microparticles prepared by double emulsion technique for controlled delivery. Saudi Pharmaceutical Journal, 2013, 21: 125-141. https://doi.org/10.1016/j.jsps.2012.05.009

[19] Mutaliyeva B, Grigoriev D, Madybekova G, et al. Microencapsulation of insulin and its release using w/o/w double emulsion method. Colloids and Surfaces a: Physicochemical and Engineering Aspects, 2017, 521: 147-152. https://doi.org/10.1016/j.colsurfa.2016.10.041

[20] Cournarie F, Savelli MP, Rosilio V, et al. Insulinloaded W/O/W multiple emulsions: comparison of the performances of systems prepared with medium-chaintriglycerides and fish oil. European Journal of Pharmaceutics and Biopharmaceutics, 2004, 58: 477-482. https://doi.org/10.1016/j.ejpb.2004.03.024

[21] Toorisaka E, Hashida M, Kamiya N, et al. An enteric-coated dry emulsion formulation for oral insulin delivery. Journal of Controlled Release, 2005, 107: 91-96. https://doi.org/10.1016/j.jconrel.2005.05.022

[22] Sakloetsakun D, Dnnhaupt S, Barthelmes J, et al. Combining two technologies: multifunctional polymers and selfnanoemulsifying drug delivery system (SNEDDS) for oral insulin administration. International Journal of Biological Macromolecules, 2013, 61: 363-372.

https://doi.org/10.1016/j.ijbiomac.2013.08.002

[23] Karamanidou T, Karidi K, Bourganis V, et al. Effective incorporation of insulin in mucus permeating selfnanoemulsifying drug delivery systems. European Journal of Pharmaceutics and Biopharmaceutics, 2015, 97: 223229.

https://doi.org/10.1016/j.ejpb.2015.04.013

[24] Samad A, Sultana Y and Aqil M. Liposomal Drug Delivery Systems: An Update Review, (n.d.).

[25] Laridi R, Kheadr EE, Benech RO, et al. Liposome encapsulated nisin Z: optimization, stability and release during milk fermentation. International Dairy Journal, 2003, 13: 325336. https://doi.org/10.1016/S0958-6946(02)00194-2

[26] Khosravi-Darani K, Pardakhty A, Honarpisheh H, et al. The role of high-resolution imaging in the evaluation of nanosystems for bioactive encapsulation and targeted nanotherapy. Micron, 2007, 38: 804-818. https://doi.org/10.1016/j.micron.2007.06.009
[27] Shehata T, Ogawara KI, Higaki K, et al. Prolongation of residence time of liposome by surface-modification with mixture of hydrophilic polymers. International Journal of Pharmaceutics, 2008, 359: 272-279. https://doi.org/10.1016/j.ijpharm.2008.04.004

[28] Yamauchi M, Tsutsumi K, Abe M, et al. Release of drugs from liposomes varies with particle size. Biological and Pharmaceutical Bulletin, 2007, 30: 963-966. https://doi.org/10.1248/bpb.30.963

[29] Taylor TM, Bruce BD, Weiss J, et al. LISTERIA MONOCYTOGENES AND ESCHERICHIA COLI O157:H7 INHIBITION IN VITRO BY LIPOSOME-ENCAPSULATED NISIN AND ETHYLENE DIAMINETETRAACETIC ACID. Journal of Food Safety, 2008, 28: 183-197. https://doi.org/10.1111/j.1745-4565.2008.00113.x

[30] Kisel MA, Kulik LN, Tsybovsky IS, et al. Liposomes with phosphatidylethanol as a carrier for oral delivery of insulin: studies in the rat. International Journal of Pharmaceutics, 2001, 216: 105-114. https://doi.org/10.1016/S0378-5173(01)00579-8

[31] Simes S, Moreira JN, Fonseca C, et al. On the formulation of $\mathrm{pH}$-sensitive liposomes with long circulation times. Advanced Drug Delivery Reviews, 2004, 56: 947-965. https://doi.org/10.1016/j.addr.2003.10.038

[32] Cui M, Wu W, Hovgaard L, et al. Liposomes containing cholesterol analogues of botanical origin as drug delivery systems to enhance the oral absorption of insulin. International Journal of Pharmaceutics, 2015, 489: 277-284. https://doi.org/10.1016/j.ijpharm.2015.05.006

[33] Zhang N, Ping Q, Huang G, et al. Transport characteristics of wheat germ agglutinin-modified insulin-liposomes and solid lipid nanoparticles in a perfused rat intestinal model. Journal of Nanoscience and Nanotechnology, 2006, 6: $2959-2966$. https://doi.org/10.1166/jnn.2006.425

[34] Kim KS, Kwag DS, Hwang HS, et al. Immense Insulin Intestinal Uptake and Lymphatic Transport Using Bile Acid Conjugated Partially Uncapped Liposome. Molecular Pharmaceutics, 2018, 15: 4756-4763. https://doi.org/10.1021/acs.molpharmaceut.8b00708

[35] Deim IT, Gmel B, Deim Z, et al. Oral Administration of Liposomal Insulin. Journal of Nanoscience and Nanotechnology, 2006, 6: 2945-2949. https://doi.org/10.1166/jnn.2006.416

[36] Wang Y, Li Z, Pan F, et al. Lytology mechanism of absorption of oral insulin liposome, En.Cnki.com.Cn.

[37] Tang Y, Heaysman CL, Willis S, et al. Physical hydrogels with self-assembled nanostructures as drug delivery systems. Expert Opinion on Drug Delivery, 2011, 8: 11411159. https://doi.org/10.1517/17425247.2011.588205

[38] Rajbhandary A and Nilsson BL. Investigating the Effects of Aromatic Amino Acids on Amphipathic Peptide SelfAssembly and Emergent Hydrogel Viscoelasticity, in: The 24th American Peptide Symposium. Prompt Scientific Publishing, 2015, 228-231. https://doi.org/10.17952/24APS.2015.228

[39] Sibiya N, Ngubane P and Mabandla M. The Ameliorative Effect of Pectin-Insulin Patch On Renal Injury in Streptozotocin-Induced Diabetic Rats. Kidney and Blood 
Pressure Research, 2017, 42: 530-540. https://doi.org/10.1159/000480395

[40] Xu H, Zhao Q, Wei G, et al. Studies on the properties and application to the oral insulin delivery of a $\mathrm{pH}$-sensitive hydrogel. Journal of Shenyang Pharmaceutical University, 2002, 19: 83-86.

[41] Yamagata T, Morishita M, Kavimandan NJ, et al. Characterization of insulin protection properties of complexation hydrogels in gastric and intestinal enzyme fluids. Journal of Controlled Release, 2006, 112: 343-349. https://doi.org/10.1016/j.jconrel.2006.03.005

[42] Peppas NA and Kavimandan NJ. Nanoscale analysis of protein and peptide absorption: insulin absorption using complexation and $\mathrm{pH}$-sensitive hydrogels as delivery vehicles. European Journal of Pharmaceutical Sciences, 2006, 29: 183-197. https://doi.org/10.1016/j.ejps.2006.04.014

[43] Besheer A, Wood KM, Peppas NA, et al. Loading and mobility of spin-labeled insulin in physiologically responsive complexation hydrogels intended for oral administration. Journal of Controlled Release, 2006, 111: 73-80. https://doi.org/10.1016/j.jconrel.2005.12.008

[44] Mahkam M. Using pH-sensitive hydrogels containing cubane as a crosslinking agent for oral delivery of insulin. Journal of Biomedical Materials Research Part B: Applied Biomaterial, 2005, 75: 108-112. https://doi.org/10.1002/jbm.b.30279

[45] Wang X, Cheng D, Liu L, et al. Development of poly(hydroxyethyl methacrylate) nanogel for effective oral insulin delivery. Pharmaceutical Development and Technology, 2018, 23: 351-357. https://doi.org/10.1080/10837450.2017.1295064

[46] Wu SJ and Robinson JR. Transport of human growth hormone across Caco- 2 cells with novel delivery agents: evidence for P-glycoprotein involvement. Journal of Controlled Release, 1999, 62: 171-177. https://doi.org/10.1016/S0168-3659(99)00035-8

[47] Leone-Bay A, Sato M, Paton D, et al. Oral delivery of biologically active parathyroid hormone. Pharmaceutical Research, 2001, 18: 964-970. https://doi.org/10.1023/A:1010936227570

[48] Starokadomskyy PL and Dubey IY. New absorption promoter for the buccal delivery: preparation and characterization of lysalbinic acid. International Journal of Pharmaceutics, 2006, 308: 149-154. https://doi.org/10.1016/j.ijpharm.2005.11.013

[49] Li L, Jiang G, Yu W, et al. Preparation of chitosan-based multifunctional nanocarriers overcoming multiple barriers for oral delivery of insulin. Materials Science \& Engineering C-Materials for Biological, 2017, 70: 278-286. https://doi.org/10.1016/j.msec.2016.08.083

[50] Maciel VBV, Yoshida CMP, Pereira SMSS, et al. Electrostatic Self-Assembled Chitosan-Pectin Nano- and Microparticles for Insulin Delivery. Molecules, 2017, 22: 1707. https://doi.org/10.3390/molecules22101707

[51] Wang Y, Huang F, Sun Y, et al. Development of shell crosslinked nanoparticles based on boronic acid-related reactions for self-regulated insulin delivery. Journal of Biomaterials Science, Polymer Edition, 2017, 28: 93-106. https://doi.org/10.1080/09205063.2016.1246289
[52] Bhattacharyya A, Mukherjee D, Mishra R, et al. Preparation of polyurethane-alginate/chitosan core shell nanoparticles for the purpose of oral insulin delivery. European Polymer Journal, 2017, 92: 294-313. https://doi.org/10.1016/j.eurpolymj.2017.05.015

[53] Lopes M, Shrestha N, Correia A, et al. Dual chitosan/albumin-coated alginate/dextran sulfate nanoparticles for enhanced oral delivery of insulin. Journal of Controlled Release, 2016, 232: 29-41. https://doi.org/10.1016/j.jconrel.2016.04.012

[54] Deng W, Xie Q, Wang H, et al. Selenium nanoparticles as versatile carriers for oral delivery of insulin: Insight into the synergic antidiabetic effect and mechanism, Nanomedicine: Nanotechnology. Biology and Medicine, 2017, 13: 19651974. https://doi.org/10.1016/j.nano.2017.05.002

[55] Lopes MA, Abrahim-Vieira B, Oliveira C, et al. Probing insulin bioactivity in oral nanoparticles produced by ultrasonication-assisted emulsification/internal gelation. International Journal of Nanomedicine, 2015, 10: 5865-5880. https://doi.org/10.2147/IJN.S86313

[56] Abramson A, Caffarel-Salvador E, Khang M, et al. An ingestible self-orienting system for oral delivery of macromolecules. Science, 2019, 363: 611-615. https://doi.org/10.1126/science.aau2277

[57] Chaudhury A and Das S. Recent advancement of chitosanbased nanoparticles for oral controlled delivery of insulin and other therapeutic agents. AAPS PharmSciTech, 2011, 12: $10-20$. https://doi.org/10.1208/s12249-010-9561-2

[58] Bravo-Osuna I, Vauthier C, Farabollini A, et al. Mucoadhesion mechanism of chitosan and thiolated chitosanpoly(isobutyl cyanoacrylate) core-shell nanoparticles. Biomaterials, 2007, 28: 2233-2243. https://doi.org/10.1016/j.biomaterials.2007.01.005

[59] Yeh TH, Hsu LW, Tseng MT, et al. Mechanism and consequence of chitosan-mediated reversible epithelial tight junction opening. Biomaterials, 2011, 32: 6164-6173. https://doi.org/10.1016/j.biomaterials.2011.03.056

[60] Mukhopadhyay P and Kundu PP. Chitosan-graft-PAMAMalginate core-shell nanoparticles: a safe and promising oral insulin carrier in an animal model. RSC Advances, 2015, 5: 93995-94007. https://doi.org/10.1039/C5RA17729D

[61] Rostamizadeh K, Rezaei S, Abdouss M, et al. A hybrid modeling approach for optimization of PMAA-chitosanPEG nanoparticles for oral insulin delivery. RSC Advances, 2015, 5: 69152-69160. https://doi.org/10.1039/C5RA07082A

[62] Su FY, Lin KJ, Sonaje K, et al. Protease inhibition and absorption enhancement by functional nanoparticles for effective oral insulin delivery. Biomaterials, 2012, 33: 28012811. https://doi.org/10.1016/j.biomaterials.2011.12.038

[63] Smith J, Wood E and Dornish M. Effect of chitosan on epithelial cell tight junctions. Pharmaceutical Research, 2004, 21: 43-49. https://doi.org/10.1023/B:PHAM.0000012150.60180.e3 
[64] Jin Y, Song Y, Zhu X, et al. Goblet cell-targeting nanoparticles for oral insulin delivery and the influence of mucus on insulin transport. Biomaterials, 2012, 33: 1573-1582. https://doi.org/10.1016/j.biomaterials.2011.10.075

[65] Liu M, Zhang J, Zhu X, et al. Efficient mucus permeation and tight junction opening by dissociable "mucus-inert" agent coated trimethyl chitosan nanoparticles for oral insulin delivery. Journal of Controlled Release, 2016, 222: 67-77. https://doi.org/10.1016/j.jconrel.2015.12.008

[66] Bernkop-Schnrch A, Hornof M and Guggi D. Thiolated chitosans. European Journal of Pharmaceutics and Biopharmaceutics, 2004, 57: 9-17. https://doi.org/10.1016/S0939-6411(03)00147-4

[67] Yin L, Ding J, He C, et al. Drug permeability and mucoadhesion properties of thiolated trimethyl chitosan nanoparticles in oral insulin delivery. Biomaterials, 2009, 30: 56915700 .

https://doi.org/10.1016/j.biomaterials.2009.06.055

[68] Uekama K. Design and evaluation of cyclodextrin-based drug formulation. Chemical and Pharmaceutical Bulletin, 2004, 52: 900-915.

https://doi.org/10.1248/cpb.52.900

[69] Zhang N, Li J, Jiang W, et al. Effective protection and controlled release of insulin by cationic beta-cyclodextrin polymers from alginate/chitosan nanoparticles. International Journal of Pharmaceutics, 2010, 393: 212-218. https://doi.org/10.1016/j.ijpharm.2010.04.006

[70] Chalasani KB, Russell-Jones GJ, Yandrapu SK, et al. A novel vitamin B12-nanosphere conjugate carrier system for peroral delivery of insulin. Journal of Controlled Release, 2007, 117: 421-429.

https://doi.org/10.1016/j.jconrel.2006.12.003

[71] Reis CP, Ribeiro AJ, Houng S, et al. Nanoparticulate delivery system for insulin: design, characterization and in vitro/in vivo bioactivity. European Journal of Pharmaceutical Sciences, 2007, 30: 392-397.

https://doi.org/10.1016/j.ejps.2006.12.007

[72] Zhenqing $\mathrm{H}$, Zhenxi Z, Chuanxin Z, et al. Use of natural plant exudates (Sanguis Draxonis) for sustained oral insulin delivery with dramatic reduction of glycemic effects in diabetic rats. Journal of Controlled Release, 2004, 97: 467-475. https://doi.org/10.1016/j.jconrel.2004.03.033

[73] Li H, Zhang Z, Bao X, et al. Fatty acid and quaternary ammonium modified chitosan nanoparticles for insulin delivery. Colloids and Surfaces B: Biointerfaces, 2018, 170: 136143.

https://doi.org/10.1016/j.colsurfb.2018.05.063

[74] Zhang Z, Li H, Xu G, et al. Liver-targeted delivery of insulin-loaded nanoparticles viaenterohepatic circulation of bile acids. Drug Delivery, 2018, 25: 1224-1233. https://doi.org/10.1080/10717544.2018.1469685

[75] Lima RA, Oliveira RR, Wataya CH, et al. Biodegradable Starch/Copolyesters Film Reinforced with Silica Nanoparticles: Preparation and Characterization. Wiley-Blackwell, Hoboken, NJ, USA, 2015. https://doi.org/10.1002/9781119093404.ch87

[76] Zhang Z, Shan H, Chen L, et al. Synthesis of pH-responsive starch nanoparticles grafted poly (l-glutamic acid) for insulin controlled release. European Polymer Journal, 2013,
49: 2082-2091.

https://doi.org/10.1016/j.eurpolymj.2013.04.032

[77] Sun L, Zhang X, Wu Z, et al. Oral glucose- and pH-sensitive nanocarriers for simulating insulin release in vivo. Polymer Chemistry, 2014, 5: 1999-2009. https://doi.org/10.1039/C3PY01416A

[78] Zhao X, Shan C, Zu Y, et al. Preparation, characterization, and evaluation in vivo of Ins-SiO-HP55 (insulin-loaded silica coating HP55) for oral delivery of insulin. International Journal of Pharmaceutics, 2013, 454: 278-284. https://doi.org/10.1016/j.ijpharm.2013.06.051

[79] Lee JE, Lee N, Kim T, et al. Multifunctional Mesoporous Silica Nanocomposite Nanoparticles for Theranostic Applications. Accounts of Chemical Research, 2011, 44: 893902.

https://doi.org/10.1021/ar2000259

[80] Nur M, Ramchandran L and Vasiljevic T. Tragacanth as an oral peptide and protein delivery carrier: Characterization and mucoadhesion. Carbohydr Polym, 2016, 143: 223-230. https://doi.org/10.1016/j.carbpol.2016.01.074

[81] Lal S, Perwez A, Rizvi MA, et al. Design and development of a biocompatible montmorillonite PLGA nanocomposites to evaluate in vitro oral delivery of insulin. Applied Clay Science, 2017, 147: 69-79. https://doi.org/10.1016/j.clay.2017.06.031

[82] Zhu S, Chen S, Gao Y, et al. Enhanced oral bioavailability of insulin using PLGA nanoparticles co-modified with cellpenetrating peptides and Engrailed secretion peptide (Sec). Drug Delivery, 2016, 23: 1980-1991. https://doi.org/10.3109/10717544.2015.1043472

[83] Liu C, Shan W, Liu M, et al. A novel ligand conjugated nanoparticles for oral insulin delivery. Drug Delivery, 2016, 23: $2015-2025$. https://doi.org/10.3109/10717544.2015.1058433

[84] Sun S, Liang N, Gong X, et al. Multifunctional Composite Microcapsules for Oral Delivery of Insulin. International Journal of Molecular Sciences, 2016, 18: 54 https://doi.org/10.3390/ijms18010054

[85] Madsen F and Peppas NA. Complexation graft copolymer networks: swelling properties, calcium binding and proteolytic enzyme inhibition. Biomaterials, 1999, 20: 17011708. https://doi.org/10.1016/S0142-9612(99)00071-X

[86] Zhao C, Zhuang X, He P, et al. Synthesis of biodegradable thermo- and $\mathrm{pH}$-responsive hydrogels for controlled drug release. Polymer, 2009, 50: 4308-4316. https://doi.org/10.1016/j.polymer.2009.07.010

[87] Gao X, He C, Xiao C, et al. Biodegradable pH-responsive polyacrylic acid derivative hydrogels with tunable swelling behavior for oral delivery of insulin. Polymer, 2013, 54 1786-1793. https://doi.org/10.1016/j.polymer.2013.01.050

[88] Zhang J, Liang X, Zhang Y, et al. Fabrication and evaluation of a novel polymeric hydrogel of carboxymethyl chitosang-polyacrylic acid (CMC-g-PAA) for oral insulin delivery. RSC Advances, 2016, 6: 52858-52867. https://doi.org/10.1039/C6RA05078F 
[89] Jain S, Rathi VV, Jain AK, et al. Folate-decorated PLGA nanoparticles as a rationally designed vehicle for the oral delivery of insulin. Nanomedicine (Lond), 2012, 7: 13111337. https://doi.org/10.2217/nnm.12.31

[90] Malathi S, Nandhakumar P, Pandiyan V, et al. Novel PLGAbased nanoparticles for the oral delivery of insulin. International Journal of Nanomedicine, 2015, 10: 2207-2218. https://doi.org/10.2147/IJN.S67947

[91] Makadia HK and Siegel SJ. Poly Lactic-co-Glycolic Acid (PLGA) as Biodegradable Controlled Drug Delivery Carrier. Polymers, 2011, 3: 1377-1397. https://doi.org/10.3390/polym3031377

[92] Xiong XY, Li YP, Li ZL, et al. Vesicles from Pluronic/poly(lactic acid) block copolymers as new carriers for oral insulin delivery. Journal of Controlled Release, 2007, 120: 11-17. https://doi.org/10.1016/j.jconrel.2007.04.004

[93] Xiong XY, Li QH, Li YP, et al. Pluronic P85/poly(lactic acid) vesicles as novel carrier for oral insulin delivery. Colloids Surf B Biointerfaces, 2013, 111: 282-288. https://doi.org/10.1016/j.colsurfb.2013.06.019

[94] Chen J and Yi YI. Study on preparation and pharmacodynamics of oral insulin-loaded poly (lactic acid) nanoparticles. Chinese Journal of Modern Applied Pharmacy, 2003.

[95] Ren J. Modification of PLA, in: Biodegradable Poly(Lactic Acid): Synthesis, Modification, Processing and Applications, Springer Berlin Heidelberg, Berlin, Heidelberg, 2011, 38-141. https://doi.org/10.1007/978-3-642-17596-1_4

[96] Wong CY, Al-Salami H and Dass CR. Potential of insulin nanoparticle formulations for oral delivery and diabetes treatment. Journal of Controlled Release, 2017, 264: 247 275.

https://doi.org/10.1016/j.jconrel.2017.09.003

[97] Boushra M, Tous S, Fetih G, et al. Development and evaluation of viscosity-enhanced nanocarrier (VEN) for oral insulin delivery. International Journal of Pharmaceutics, 2016, 511: $462-472$. https://doi.org/10.1016/j.ijpharm.2016.07.016

[98] Hecq J, Amighi K and Goole J. Development and evaluation of insulin-loaded cationic solid lipid nanoparticles for oral delivery. Journal of Drug Delivery Science and Technology, 2016, 36: 192-200. https://doi.org/10.1016/j.jddst.2016.10.012

[99] Ansari MJ, Anwer MK, Jamil S, et al. Enhanced oral bioavailability of insulin-loaded solid lipid nanoparticles: pharmacokinetic bioavailability of insulin-loaded solid lipid nanoparticles in diabetic rats. Drug Delivery, 2016, 23: 1972-1979. https://doi.org/10.3109/10717544.2015.1039666

[100] He H, Wang P, Cai C, et al. VB12-coated Gel-Core-SLN containing insulin: Another way to improve oral absorption. International Journal of Pharmaceutics, 2015, 493: 451459.

https://doi.org/10.1016/j.ijpharm.2015.08.004
[101] Zhao P, Yin W, Wu A, et al. Dual-Targeting to Cancer Cells and M2 Macrophages via Biomimetic Delivery of Mannosylated Albumin Nanoparticles for Drug-Resistant Cancer Therapy. Advanced Functional Materials, 2017, 27: 1700403. https://doi.org/10.1002/adfm.201700403

[102] Zhang Z, Cai H, Liu Z, et al. Effective Enhancement of Hypoglycemic Effect of Insulin by Liver-Targeted Nanoparticles Containing Cholic Acid-Modified Chitosan Derivative. Molecular Pharmaceutics, 2016, 13: 2433-2442. https://doi.org/10.1021/acs.molpharmaceut.6b00188

[103] Xu B, Jiang G, Yu W, et al. Preparation of poly(lactic-coglycolic acid) and chitosan composite nanocarriers via electrostatic self assembly for oral delivery of insulin. Materials Science \& Engineering C-Materials for Biological, 2017, 78: $420-428$. https://doi.org/10.1016/j.msec.2017.04.113

[104] Song H, Ma X, Xiong F, et al. Preparation and evaluation of insulin-loaded nanoparticles based on hydroxypropyl- $\beta$ cyclodextrin modified carboxymethyl chitosan for oral delivery. Journal of Wuhan University of Technology-Mater, 2016, 31: 1394-1400. https://doi.org/10.1007/s11595-016-1544-z

[105] Li L, Yang L, Li M, et al. A cell-penetrating peptide mediated chitosan nanocarriers for improving intestinal insulin delivery. Carbohydr Polym, 2017, 174: 182-189. https://doi.org/10.1016/j.carbpol.2017.06.061

[106] Fan W, Xia D, Zhu Q, et al. Functional nanoparticles exploit the bile acid pathway to overcome multiple barriers of the intestinal epithelium for oral insulin delivery. Biomaterials, 2018, 151: 13-23.

https://doi.org/10.1016/j.biomaterials.2017.10.022

[107] Patil NH and Devarajan PV. Insulin-loaded alginic acid nanoparticles for sublingual delivery. Drug Delivery, 2016, 23: 429-436. https://doi.org/10.3109/10717544.2014.916769

[108] Alibolandi M, Alabdollah F, Sadeghi F, et al. Dextran-bpoly(lactide-co-glycolide) polymersome for oral delivery of insulin: In vitro and in vivo evaluation. Journal of Controlled Release, 2016, 227: 58-70. https://doi.org/10.1016/j.jconrel.2016.02.031

[109] Ansari MJ, Anwer MK, Jamil S, et al. Enhanced oral bioavailability of insulin-loaded solid lipid nanoparticles: pharmacokinetic bioavailability of insulin-loaded solid lipid nanoparticles in diabetic rats. Drug Delivery, 2016, 23: 1972-1979. https://doi.org/10.3109/10717544.2015.1039666

[110] He H, Wang P, Cai C, et al. VB12-coated Gel-Core-SLN containing insulin: Another way to improve oral absorption. International Journal of Pharmaceutics, 2015, 493: 451459. https://doi.org/10.1016/j.ijpharm.2015.08.004

[111] Guo Y and Pratap Singh A. Emerging technologies in buccal and sublingual drug administration. Journal of Drug Delivery Science and Technology, 2019, 52: 440-451. https://doi.org/10.1016/j.jddst.2019.05.014 